

NBSIR 74.465

Shear and Tension-Bending Fatigue
Test Methods for Threaded
Airframe Fasteners

D. J. Chwirut, D. E. Marlowe, and J.S. Steel

Engineering Mechanics Section

Mechanics Division

Institute for Basic Standards

National Bureau of Standards

Washington, D. C. 20234

September 1974

Prepared for

Aero Structures Department

Naval Air Development Center

Department of the Navy

Warminster, Pennsylvania 18974 

NBSIR 74- 465

\section{SHEAR AND TENSION-BENDING FATIGUE TEST METHODS FOR THREADED AIRFRAME FASTENERS}

D.J.Chwirut, D.E. Marlowe, and J.S. Steel

Engineering Mechanics Section

Mechanics Division

Institute for Basic Standards

National Bureau of Standards

Washington, D. C. 20234

September 1974

Prepared for

Aero Structures Department

Naval Air Development Center

Department of the Navy

Warminster, Pennsylvania 18974

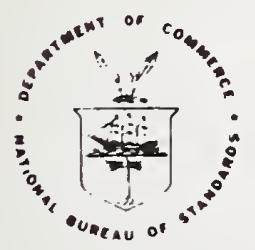

U. S. DEPARTMENT OF COMMERCE, Froderick B. Dent, Secretary

NATIONAL BUREAU OF STANDARDS, Richard $w$. Roberts. Director 
1. INTRODUCTION . . . . . . . . . . . . . . . . . 1

2. PROGRAM •. . . . . . . . . . . . . . . . . . . 2

2.1 Single Shear Fatigue . . . . . . . . . . . . . 2

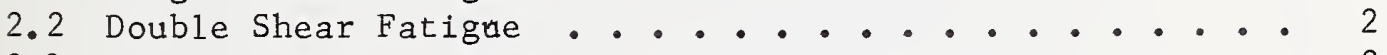

2.3 Tension-Bending Fatigue . . . . . . . . . . . . 2

3. TEST METHOD DEVELOPMENT • . . . . . . . . . . . . . 2

3.1 Single Shear . . . . . . . . . . . . . . 2

a. Specimens . . . . . . . . . . . . . . 2

b. Test Equipment . . . . . . . . . . . . . 2

c. Test Procedure .. . . . . . . . . . . . 3

d. Test Results .................. . 3

3.2 Double Shear . . . . . . . . . . . . . . 4

a. Specimens . . . . . . . . . . . . . . 4

b. Test Equipment .... . . . . . . . . . . 4

c. Test Procedure ................ 5

d. Test Results . . . . . . . . . . . . . 6

3.3 Tension-Bending . . . . . . . . . . . . . . 7

a. Specimens... . . . . . . . . . . . . 7

b. Test Equipment . . . . . . . . . . . . . 7

c. Test Procedure .. . . . . . . . . . . 8

d. Test Results . . . . . . . . . . . . 8

4. CONCLUSIONS . . . . . . . . . . . . . . . . . 9

5. CLOSURE • . . . . . . . . . . . . . . . . . 10 


\title{
SHEAR AND TENSION-BENDING FATIGUE TEST METHODS FOR THREADED AIRFRAME FASTENERS
}

Daniel J. Chwirut, Donald E. Marlowe, and James S. Steel*

\begin{abstract}
Fatigue test methods for threaded airframe fasteners loaded in other than direct tension are described. The types of loading considered are single shear, double shear, and tension-bending. The test fixtures used in these tests are described. Results of tests on lots of fasteners from different manufacturers indicate that fasteners considered identical on the basis of direct tension procurement tests exhibit different fatigue life characteristics when loaded in shear and/or tension-bending. Thus the test methods described herein may be of future value as procurement tests for airframe fasteners.
\end{abstract}

Key words: Airframe fastener; double shear; fatigue; single shear; tension-bending; test methods.

\section{INTRODUCTION}

Current military procurement practices require only a limited amount of fatigue testing to verify the quality of threaded airframe fasteners. In the case of high strength tension bolts such as the $160,0001 \mathrm{bf} / \mathrm{in}^{2}$ $\left(11.0 \times 10^{8} \mathrm{~N} / \mathrm{m}^{2}\right)$ and $180,000 \mathrm{lbf} / \mathrm{in}^{2}\left(12.4 \times 10^{8} \mathrm{~N} / \mathrm{m}^{2}\right)$ series, verification of fatigue resistance is based upon axial tension fatigue tests. Under this type of loading, failures are expected in the threaded section of the fastener.

In service, however, few fasteners experience simple tension. Most experience a combination of loads including single shear, double shear, and/or bending. Under these conditions fatigue failures have occurred in the shoulders of fasteners from lots which passed the tension fatigue acceptance tests. This suggests that the standard axial tension fatigue test [1] is an inadequate measure of the fatigue resistance qualities of fasteners in service.

The investigation reported herein was undertaken to establish standard fatigue test methods for airframe fasteners loaded in shear and combinations of tension and bending. This work was performed at the National Bureau of Standards under the sponsorship and with the financial assistance of the United States Navy, Naval Air Development Center, Warminster, Pennsylvania.

*Present address, Fire Technology Division, NBS 


\section{PROGRAM}

Three different test conditions were investigated in this study. They were designed to produce the type of failures which have occurred in fasteners in service.

\subsection{Single Shear Fatigue}

The single shear test was designed to produce the type of failure experienced by flush head fasteners when used in a single lap joint configuration. The prying action imparted to the head of the fastener causes a catastrophic failure at the fastener shoulder, i.e. complete separation of the head from the shank of the fastener.

\subsection{Double Shear Fatigue}

Because of difficulties in the testing of fasteners in single shear, the double shear test was designed. In this test, the prying action on the head of the bolt causes failure initiation at the shoulder of the fastener near one joint interface, but catastrophic failure cannot occur since the shank can still carry the load at the other interface.

\subsection{Tension-Bending Fatigue}

The tension-bending test was designed to simulate the effects of induced bending in nominally direct tension loading configurations. Whereas fasteners loaded in direct tension should fail in the threads, the introduction of some bending causes the head-to-shank fillet to become the critical crack location and the fastener fails catastrophically with the head separating from the shank.

\section{TEST METHOD DEVELOPMENT}

\subsection{Single Shear}

\section{a. Specimens}

Single shear fatigue testing was conducted using 0.25 in $(0.6 \mathrm{~cm})$ diameter, $85,000 \mathrm{lbf} / \mathrm{in}\left(5.86 \times 10^{8} \mathrm{~N} / \mathrm{m}^{2}\right)$ tensile strength 100 flush head Easteners with steel washers and self locking nuts. These fasteners had Phillips wrenching recesses.

\section{b. Test Equipment}

The testing program was conducted in two electrohydraulic fatigue machines. The rated capacities of these machines are 10,000 $1 \mathrm{bf}(44,480 \mathrm{~N})$ and $50,000 \operatorname{lbf}(222,400 \mathrm{~N})$.

The single shear test fixtures are shown in figures 1 and 2. Three sets of fixtures were designed, with plate thicknesses as indicated in figure 2. In each set, the thickness of plate A supporting the bolt head is half the thickness of plate B. When load is applied to this eccentric 
joint, most of the flexure occurs as bending of plate $A$ and thus loads the head of the bolt in a prying action. The total thickness of the two plates was approximately equal to the fastener grip length.

Spaulding [2] has shown that the stress concentration in a flush head fastener due to pinching by a countersunk plate is essentially constant for ratios of plate thickness to countersink depth greater than approximately 1.2. Since it is desirable to have this stress concentration constant for tests on all lengths of fasteners, a minimum thickness of plate A of approximately 1.2 times the fastener head height is established. As previously mentioned, to insure the proper loading on the bolt head, plate $B$ should be twice as thick as plate A. Thus the shortest fastener that can be tested must have a grip length of at least 3.6 times the head height.

All plates were 3 in $(7.6 \mathrm{~cm})$ wide and 17.6 in $(44.8 \mathrm{~cm})$ long. This length is the maximum compatible with the crosshead clearance of the 10,000 lbf $(44,480 \mathrm{~N})$ capacity fatigue machine.

The $100^{\circ}$ countersink was machined to a depth such that the head of the fastener was flush with the surface of the shear plate. The plates were AISI 4130 alloy steel hardened to about Rockwell C45.

\section{c. Test Procedure}

The test fastener, washer, nut, and fixtures were washed with acetone or were vapor degreased with trichloroethylene prior to testing. This is necessary to remove any lubrication on the bolt which may cause an increase in fastener fatigue life [3].

A nominal torque of $10 \mathrm{lbf}-\mathrm{in}(1.1 \mathrm{~N}-\mathrm{m})$ was applied to the fastener and nut before each test. This torque was large enough to draw the plates together but was judged not large enough to increase the fatigue life of the fasteners through preload as noted by Mordfin [4].

The maximum cyclic loads were taken as percentages of the single shear static strength of test fasteners. Loads were generally in the range of 40 to 90 percent of the static strength. The minimum cyclic load was 10 percent of the maximum. All tests were conducted at $10 \mathrm{~Hz}$.

Specimen failure, as indicated by the inability of the fastener to sustain the test load, caused automatic machine shutdown.

\section{d. Test Results}

Tests on two different lengths of 0.25 in $(0.6 \mathrm{~cm})$ diameter, $100^{\circ}$ flush head fasteners indicated that the stress concentration factor in the fastener caused by the countersunk shear plate was not essentially constant as predicted, indicating that spaulding's results [2] may not be applicable to this particular loading configuration. Therefore, the single shear fatigue life of such fasteners is not independent of fastener length. For example, at one test load, all 8 of the longer 
fasteners failed between 56,000 and 125,000 cycles of load, whereas 42 of the 44 shorter fasteners had not failed after 150,000 cycles of load.

When load is applied to the single shear lap joint, the plates bend due to the eccentricity of the joint configuration. In tests on the longer fasteners, because the plates are thick, this bending was slight and most of the load was transferred to the test fastener in shear of the bolt shank and prying of the bolt head. In tests on the shorter fasteners, the thinner plates flexed considerably, and a larger portion of the load was carried by the test fastener head in direct tension, which is apparently not as critical a type of loading as the prying of the head in shear.

Because of this fixture limitation, it was decided that a symmetric double shear test configuration might yield a more consistent transfer of load to the test fastener, and provide a test method which would be independent of fastener length.

\subsection{Double Shear}

\section{a. Specimens}

The double shear test method was developed using 0.25 in $(0.6 \mathrm{~cm})$ diameter, $85,000 \mathrm{lbf} / \mathrm{in}^{2}\left(5.86 \times 10^{8} \mathrm{~N} / \mathrm{m}^{2}\right)$, $100^{\circ}$ flush head fastener with steel washers and self locking nuts, and four sizes of 160,000-180,000 lbf/in ${ }^{2}\left(11.0 \times 10-12.4 \times 10^{8} \mathrm{~N} / \mathrm{m}^{2}\right)$ series, $100^{\circ}$ flush head fasteners with steel washers and self locking nuts. Both types of fasteners tested had Phillips wrenching recesses. A program to determine the ability of the test method to distinguish between lots of fasteners from different manufacturers was undertaken using three sizes of $160,000-180,0001 \mathrm{bf} / \mathrm{in}^{2}$ $\left(11.0 \times 10^{8}-12.4 \times 10^{8} \mathrm{~N} / \mathrm{m}^{2}\right)$ series, $100^{\circ} \mathrm{flush}$ head fasteners obtained from U. S. Navy supply depots.

\section{b. Test Equipment}

This testing program was conducted in the same two testing machines described previously.

The double shear test fixtures are shown in the photograph in figure 3 and schematically in figure 4 . The side plates of the joint are simulated by the small inserts as shown in figure 5 .

Head angle measurements on test fasteners indicated that most fasteners have head angles a few minutes of arc less than the nominal 100 degrees. In order to insure loading on the fastener head and precipitate shoulder failures, a 98 - 99 degree countersink angle was used. Complete engineering drawings for these fixtures are given in Appendix A.

As mentioned earlier, failure of the shoulder in a double shear test does not cause catastrophic failure of the test joint since the shank can still support the load. However, to decrease the scatter in fatigue life 
data, it was decided to consider initiation of shoulder cracking as failure of the fastener. To detect this failure, a fatigue crack initiation detector was developed [5]. This device is shown installed on the test fixtures in figure 3.

A dc linear variable differential transformer (DCDT) is mounted as shown in figure 3 with the armature secured to one test fixture and the coil to the other fixture. The voltage output of the DCDT is thus directly related to the relative positions of the two test fixtures, and the output form and frequency approximate the waveform and frequency of the mechanical forcing function (applied loads). A block diagram of the equipment comprising the crack initiation detector is shown in figure 6 . The dc voltage supply powers the DCDT and provides the bias voltage to the circuits of the peak amplifier. The voltage output of the peak amplifier is proportional to the signal from the DCDT when the test fastener is experiencing the maximum cyclic load. The peak amplifier output is recorded on one axis of an $\mathrm{X}-\mathrm{Y}$ recorder. A circuit diagram for the peak amplifier detector circuit is shown in figure 7 . It should be noted that the first stage amplifier gain, and therefore the total detector gain, is a function of operating frequency because of the presence of capacitor Cl. As a result, the fatigue test frequency must remain constant for the duration of the test.

The signal to the other axis of the $\mathrm{X}-\mathrm{Y}$ recorder is proportional to the number of load cycles applied to the specimen. The record for each test is a plot of number of cycles versus change in relative position of test fixtures at maximum load. As a fatigue crack is initiated and propagates through the fastener, changes in the relative position of the test fixtures of 0.00002 in $(0.0005 \mathrm{~mm})$ can be resolved. Experience gained from approximately 550 tests using this system indicates that changes of 0.0001 in $(0.0025 \mathrm{~mm})$ in fixture position correlated with crack initiation in the fillet of the bolt.

\section{c. Test Procedure}

The test fastener, washer, nut and test fixtures were washed with acetone prior to testing. The tightening torque was 5, 15, 75 and 205 lbf-in for 0.190 (No. 10), $0.250,0.375$, and 0.500 in $(0.5,1.7,8.5$ and $23.1 \mathrm{~N}-\mathrm{m}$ for $0.483,0.635,0.952$, and $1.27 \mathrm{~cm}$ ) diameter fasteners respectively. For tests on fasteners longer than those for which the Iixtures were designed, a solid stainless steel spacer was inserted between the washer and test fixtures.

The maximum cyclic loads were taken as percentages of the double shear static strength of the specimen. Loads were generally in the range of 40 to 70 percent of the static strength. For each test the minimum cyclic load was 10 percent of the maximum. Cyclic speeds ranged from $5-10 \mathrm{~Hz}$. 
Fatigue failure was defined as initiation of a crack at the fastener shoulder, and was detected by the fatigue crack initiation detector. This device was connected to the error detector interlock system of the testing machine through a meter relay to shut down the machine shortly after crack initiation.

\section{d. Test Results}

Using the $85,0001 \mathrm{bf} / \mathrm{in}^{2}\left(5.86 \times 10^{8} \mathrm{~N} / \mathrm{m}^{2}\right)$ series fasteners, a series of double shear development tests were run to determine the optimum combination of fixture variables for reproducing service fallures. The parameters considered and optimum values obtained are as follows:

Hardness of side plate material under fastener head

Countersink angle

Body hole size

Fastener orientation

Web thickness (figure 5, dimension A)
$R_{c} 40-50$

98-99 degrees

$\mathrm{D}+\underset{\text { minimum }}{0.010 \text { inch }}(\mathrm{D}+0.025 \mathrm{~cm})$

no effect

$\leq 0.1 \times \mathrm{D}$

These values are incorporated in the final design of the fixtures as given in Appendix A. Fastener length had no effect on the fatigue life of fasteners tested in these fixtures. Changes in test frequency, within the range used, had no effect on results. Also during this phase of the program, the fatigue crack initiation detector [5] was developed.

An attempt to determine the ability of these test fixtures to distinguish between fasteners of different quality was made using four sizes of $160,000-180,0001 \mathrm{bf} / \mathrm{in}^{2}\left(11.0 \times 10^{8}-12.4 \times 10^{8} \mathrm{~N} / \mathrm{m}^{2}\right)$ series flush head fasteners. A complete set of reference sample data on a uniform set of fasteners obtained from one manufacturer was generated. This included at least seven replicate tests at each load level. When the test loads are normal1zed with respect to the fastener double shear strength, the median fatigue life curves and limits of the 0.95 confidence interval on the median appear as in figure 8. It appears that, when plotted on a normalized basis, the data from all sizes of a series of fastener may be considered as belonging to the same population.

Two lots of this same type of fastener were obtained from stock maintained by the U. S. Navy. These are identified as Stock Samples Nos. 1 and 2 .

Figure 9 shows results of at least seven tests at each of two load levels on each of three sizes of fasteners taken from Stock Sample No. 1. 
The 0.95 confidence interval for the median for the tests of 0.25 in diameter fasteners from the reference sample, which is representative of the data for other sizes (see figure 8), is also given for comparison.

Figure 10 shows similar results for tests on fasteners from Stock Sample No. 2. The 0.95 confidence limits for the 0.25 in diameter fasteners from the reference sample are also shown.

It was observed that the two stock samples of 0.25 in diameter fasteners, although obtained from two different supply depots, had the same manufacturer's lot number on the labels on the shipping boxes. Thus the two sets of stock sample data may not be independent and may actually comprise only a single set of data.

The scatter of fatigue life values of fasteners tested as stock samples is somewhat greater than that of fasteners tested in the reference group. However, the median of each size generally falls within the 0.95 confidence interval, indicating that these lots were of the same quality when loaded in double shear. No conclusions regarding the ability of this method to distinguish fasteners of different quality can be drawn from the results of these tests.

\subsection{Tension-Bending}

\section{a. Specimens}

The tension-bending test method was developed using 0.25 in $(0.6 \mathrm{~cm})$ diameter, $125,0001 \mathrm{bf} / \mathrm{in}^{2}\left(8.62 \times 10^{8} \mathrm{~N} / \mathrm{m}^{2}\right)$ tensile strength hexagonal head fasteners and 0.25 in $(0.6 \mathrm{~cm})$ diameter, $180,0001 \mathrm{bf} /$ in $^{2}\left(12.4 \mathrm{x} 10^{8}\right.$ $\mathrm{N} / \mathrm{m}^{2}$ ) tensile strength 12 point external wrenching fasteners with fatigue test nuts. No washers were used for these tests. The ability of this test method to distinguish between lots of fasteners from different manufacturers was determined using 0.25 in $(0.6 \mathrm{~cm})$ diameter, 125,000 $1 \mathrm{bf} / \mathrm{in}^{2}\left(8.62 \times 10^{8} \mathrm{~N} / \mathrm{m}^{2}\right)$ tensile strength hexagonal head $\mathrm{fasteners}$ taken from U. S. Navy supply depots.

\section{b. Test Equipment}

This program was conducted in the same two testing machines described previous1y.

The tension-bending test fixtures are shown in the photograph in figure 11 and schematically in figure 12. These fixtures can apply loads to the fastener in four constant (i.e., independent of load) ratios of bending stress to axial stress, in addition to direct tension. The fixtures are similar to those described by Larson and Radzimovsky [6]. Complete engineering drawings for these fixtures are given in Appendix B.

For alinement of the testing machine and measurement of bending strains induced in test fasteners by the tension-bending fixtures, a 
hexagonal head fastener with four resistance strain gages mounted at the midlength of the shank was used. This device is shown in Figure 13.

\section{c. Test Procedure}

Prior to testing, the bending strain measurement device was used to aline the testing machine. This procedure was used to minimize undesirable bending strains. Bending strain measurements taken periodically during the test program indicate that for fasteners tested in direct tension, the bending stress caused by machine misalinement did not exceed ten percent of the axial stress.

The amount of bending strain induced in the specimens by the tensionbending fixtures was measured using the bending strain measurement device. The first three knife-edge positions of the tension-bending fixtures produced ratios of maximum bending stress to axial stress of 1.7. 3.2. and 5.4 in the two types of 0.25 in $(0.6 \mathrm{~cm})$ diameter fasteners tested.

The test specimen and fixtures were washed with acetone prior to each test. When the specimen was inserted in the test fixtures, care was taken to leave two unengaged threads between the top nut surface and the fastener runout thread so as not to superimpose the stress concentrations at these locations. No washers were used.

The maximum cyclic loads were taken as percentages of the static direct tension breaking load for that series of fastener. Loads were generally in the range of 20 to 70 percent of the static strength. The minimum cyclic load was 10 percent of the maximum applied load. Test frequencies were between 2 and $10 \mathrm{~Hz}$.

All tests resulted in the catastrophic fallure of the fastener, either in the threads or at the head-to-shank fillet. Failure caused automatic machine shut-down and terminated the test.

\section{d. Test Results}

The development of the tension-bending fixtures was accomplished using a uniform set of 0.25 in $(0.6 \mathrm{~cm})$ diameter, $125,000 \mathrm{lbf} / \mathrm{in}^{2}(8.62 \mathrm{x}$ $10^{8} \mathrm{~N} / \mathrm{m}^{2}$ ) tensile strength hexagonal head fasteners obtained from one manufacturer. These fixtures can apply loads in constant ratios of bending stress to axial stress and can duplicate service failures, i.e., thread failures in direct tension and shoulder failures with induced bending. Another series of tests was run using 0.25 in $(0.6 \mathrm{~cm})$ diameter, $180,000 \mathrm{lbf} / \mathrm{in}^{2}\left(12.4 \times 10^{8} \mathrm{~N} / \mathrm{m}^{2}\right)$ tensile strength, 12-point external wrenching fasteners. These also yielded the desired mode of failure. Because of time limitations, no study on the effect of varying fixture dimensions on failure mode was made.

The ability of these fixtures to distinguish between fasteners of different quality was demonstrated using the hexagonal head fasteners. A complete set of reference sample data on a set of fasteners obtained from one manufacturer was generated. This included at least five 
replicate tests at each load level and each bending stress-to-axial stress ratio. In addition, three lots of hexagonal head fasteners of unknown origin were obtained at random from stocks of replacement fasteners maintained by the U.S. Navy. These lots were identified as stock samples $N, P$, and Q.

The results of tests performed on fasteners from stock sample $\mathrm{N}$ are shown in figure 14. At least three tests were performed at each of three load levels at each bending stress-to-axial stress ratio. The curves shown are the median fatigue life curves for the control sample. At each load level and bending stress-to-axial stress ratio, the median lifetime failure point is indicated along with the range of $\mathrm{fatigue} \mathrm{lives} \mathrm{for} \mathrm{all}$ fasteners tested at that load level and bending stress-to-axial stress ratio.

The results from similar tests performed on fasteners taken from stock samples $P$ and $Q$ are shown in figures 15 and 16 , respective1y.

The data for the stock sample fasteners loaded in direct tension generally fall on or near the median curve for the control sample. The fatigue lives of the stock sample fasteners loaded with induced bending stresses are generally somewhat shorter than the fatigue lives for the control sample fasteners tested under similar loading conditions. Thus it seems that the stock fasteners, although considered acceptable on the basis of direct tension fatigue tests, were inferior to the control sample when loaded in tension-bending fatigue.

\section{CONCLUSIONS}

Based on the tests conducted during this program, the following conclusions may be drawn:

1. A single shear lap joint should not be used for the determination of shear properties of flush head fasteners. The variations in fixture geometry necessary to accommodate fasteners of different lengths cause significantly different test results in nominally identical fasteners.

2. The double shear test fixtures described herein can consistently reproduce the shear-type head failures incurred in service in 100 degree flush head fasteners. This method has been verified using two type of fasteners obtained from one manufacturer and two samples of one type taken from Navy stock.

3. The tension-bending fixtures described herein can produce constant ratios of bending stress to axial stress in hexagonal head fasteners. Failure caused by direct tension fatigue, which occur in 
the threads, can be distinguished from failures caused by bending fatigue, which occur at the head-to-shank fillet.

4. The tension-bending method described herein can distinguish between fasteners which are nominally identical when loaded in direct tension fatigue, but which exhibit different fatigue behavior when loaded in combinations of bending and tension. Note, however, that this conclusion is based on a limited number of tests of one size of one type fastener.

\section{CLOSURE}

Test fixtures capable of consistently reproducing service-type failures for shear and tension-bending loading have been developed. However, these methods have been used on relatively small samples of a few types of fasteners. In order to fully verify the validity of these test methods to discriminate between fasteners of different quality, it is necessary to test fasteners from lots whose quality is previously known. To accomplish this, the relative quality of nominally identical fasteners purchased from different manufacturers should be determined through careful documentation of service failures. Fatigue-life curves should then be developed for these fasteners using the test methods described in this report. The validity of the test method can then be judged by comparison of the laboratory data with the service failure data. 


\section{REFERENCES}

[1] Anon, Tension Fatigue Test Procedure for Aeronautical Fasteners. National Aircraft Standard 1069 (1959), Aerospace Industries, Assn. of America, Washington, D. C.

[2] Spaulding, E. H., Detail Design for Fatigue in Aircraft Wing Structures, Metal Fatigue, G. Sines, ed, McGraw-Hill Book Co., N. Y. (1959).

[3] Viglione, J., The Effect of Nut Design on the Fatigue Life of Internal Wrenching Bolts, U. S. Naval Air Engineering Center, Report No. NAEC-AML-1910, (1964).

[4] Mordfin, L., Some Problems of Fatigue of Bolts and Bolted Joints in Aircraft Applications, NBS Tech. Note 136 (1962).

[5] Marlowe, D. E., and Steel, J. S., A Fatigue Crack Initiation Detector, J. Matls, JMLSA, I, 1 (March 1972).

[6] Larson, D. S. and Radzimovsky, E. I., The Strength of Bolted Assemblies Subjected to Combined Dynamic Loads. Presented at Society of Automotive Engineers Mid-Year Meeting, Detroit, Michigan (June 6-10, 1966). 


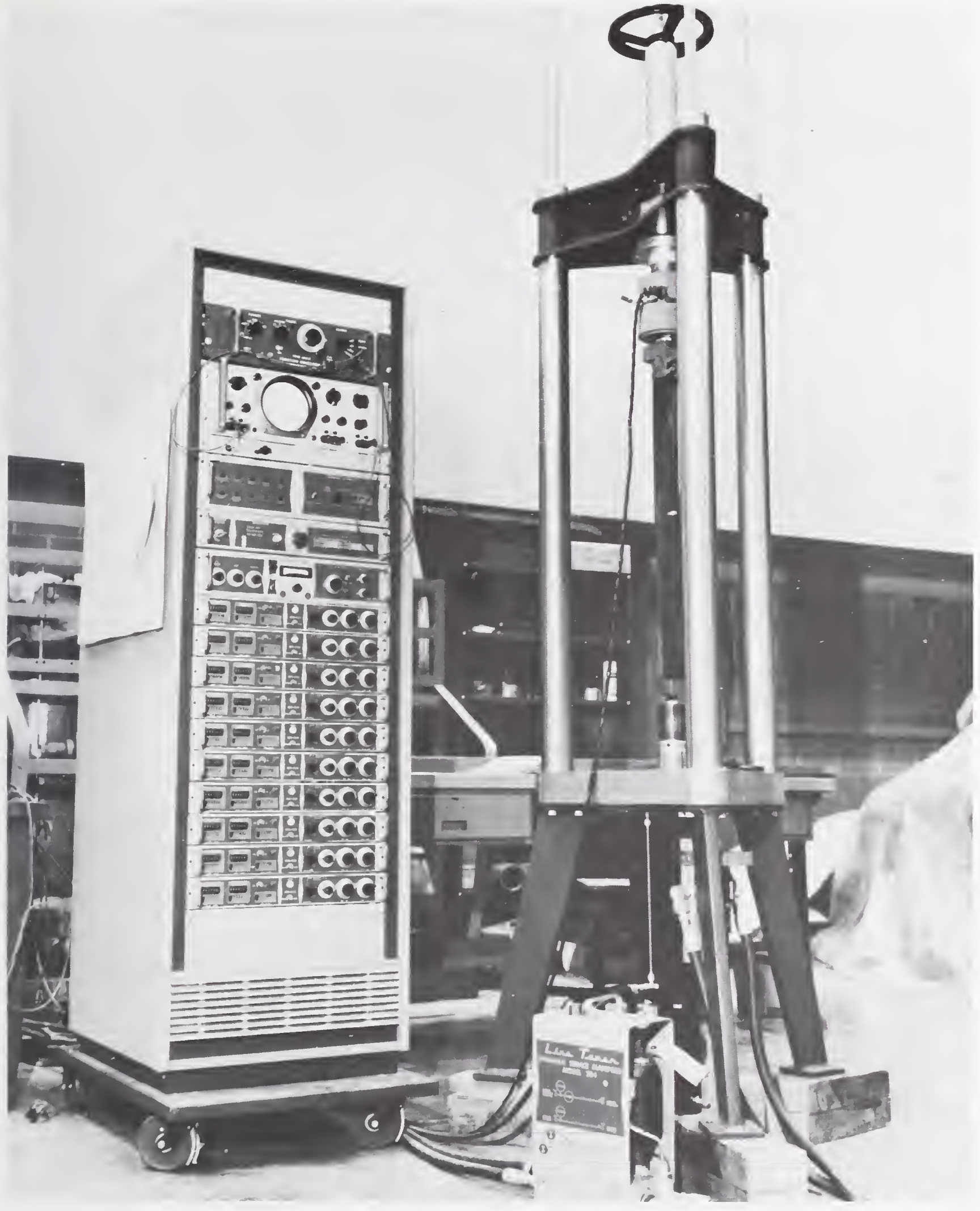

Figure 1 - Laboratory setup for single shear fatigue testing. 


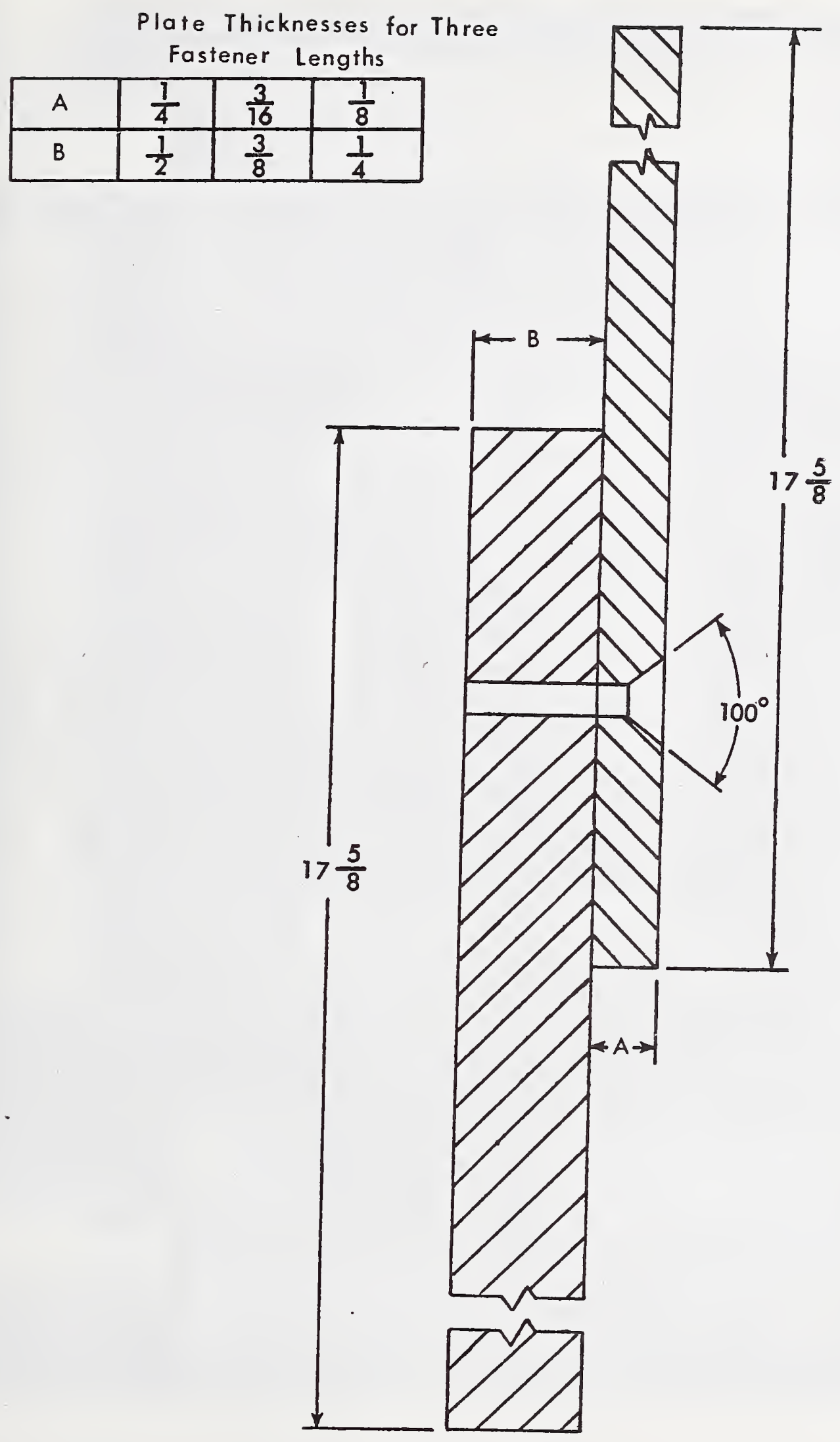

Figure 2 - Full section of single shear test fixture near specimen. Length dimensions are in inches $(1$ in $=2.54 \mathrm{~cm}$ ). 


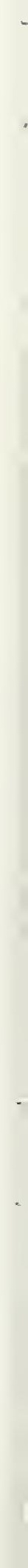




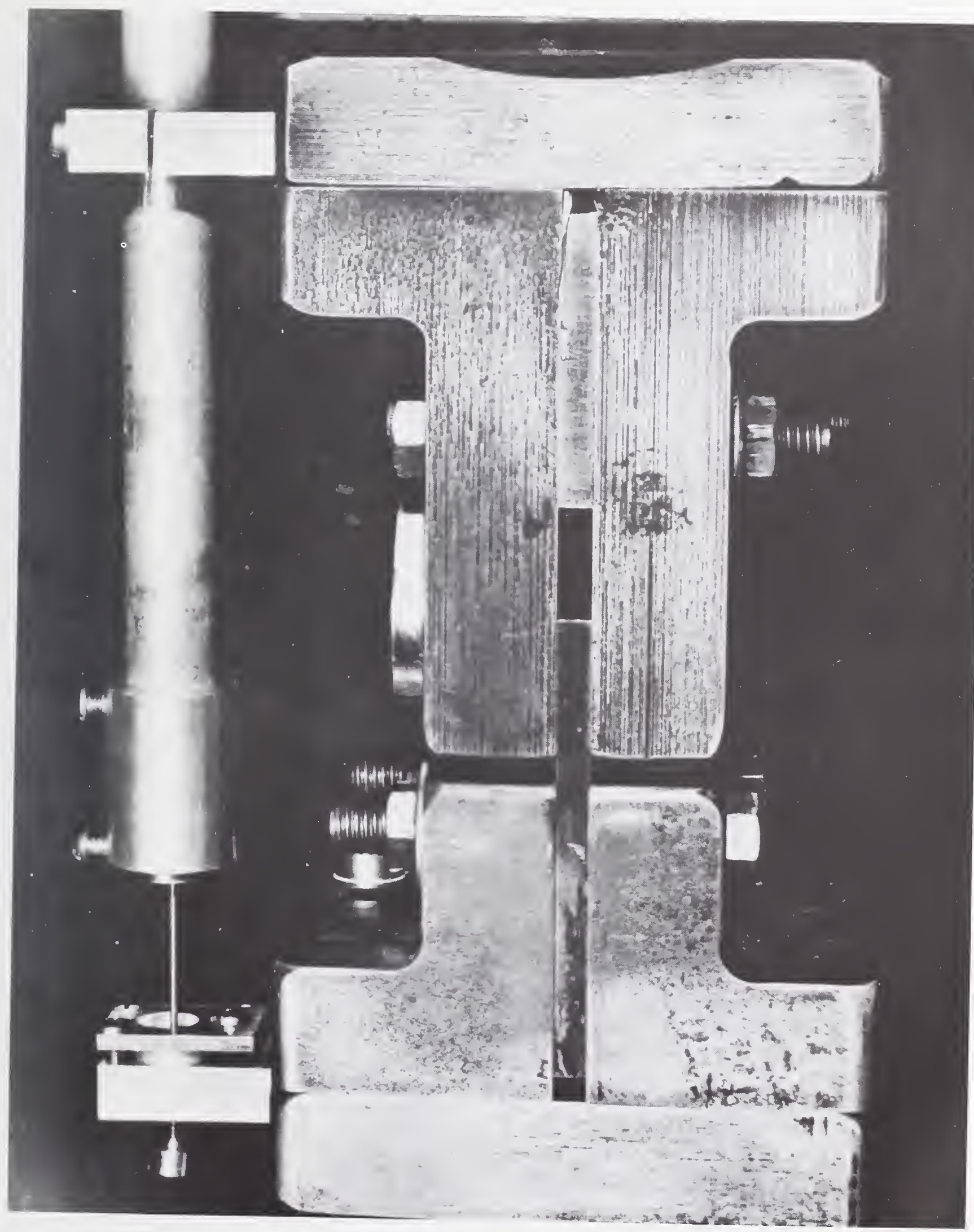

Figure 3 - Double-shear fatigue test fixtures with LVDT crack initiation detector. 


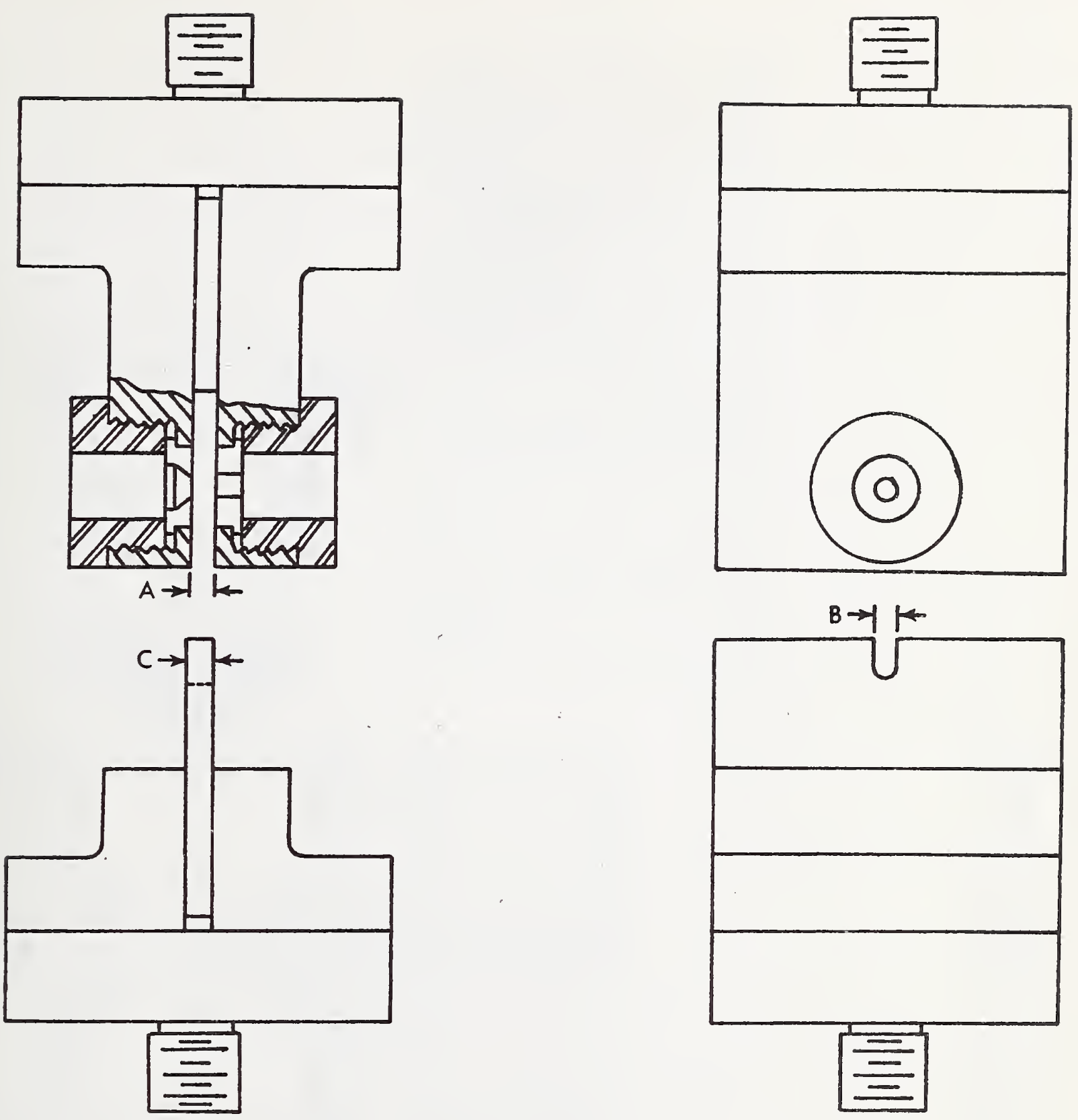

\begin{tabular}{|c|c|c|c|}
\hline BOLT SIZE & A & B & C \\
\hline 10 & .190 & .190 & .188 \\
\hline$\frac{1}{4}$ & .250 & .250 & .249 \\
\hline$\frac{3}{8}$ & .375 & .377 & .375 \\
\hline$\frac{1}{2}$ & .500 & 500 & .500 \\
\hline
\end{tabular}

Figure 4-Schematic of double shear fatigue test fixture. Length dimensions are in inches $(1 \mathrm{in}=254 \mathrm{~cm}$ ). 


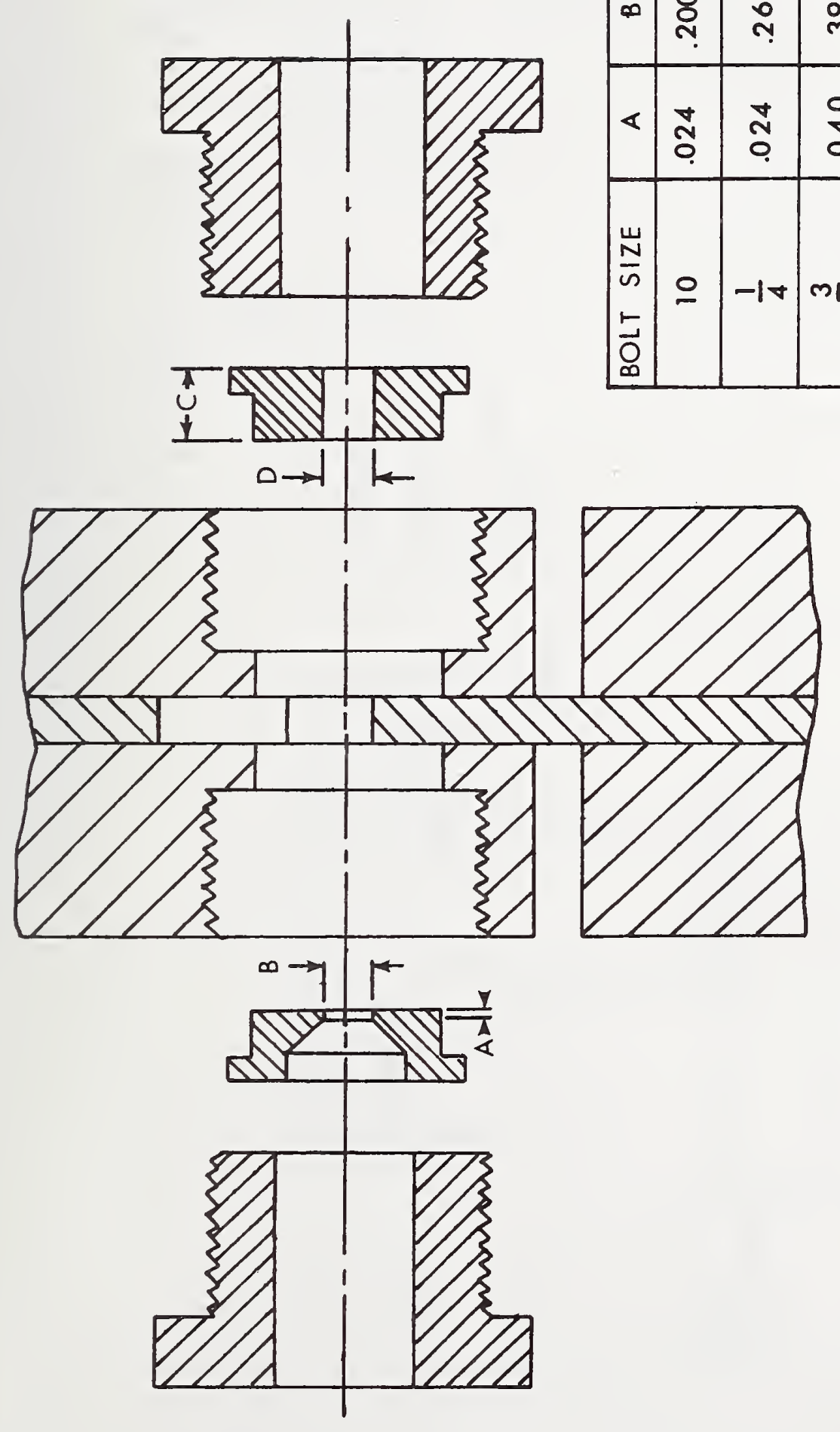

$\frac{\dot{0}}{\frac{1}{2}}$

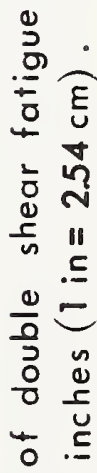

$\pm$

는

है

ㅇํํ 든

$\stackrel{\circ}{\circ}$

. $\frac{.}{0}$

б

E

它

1

约 



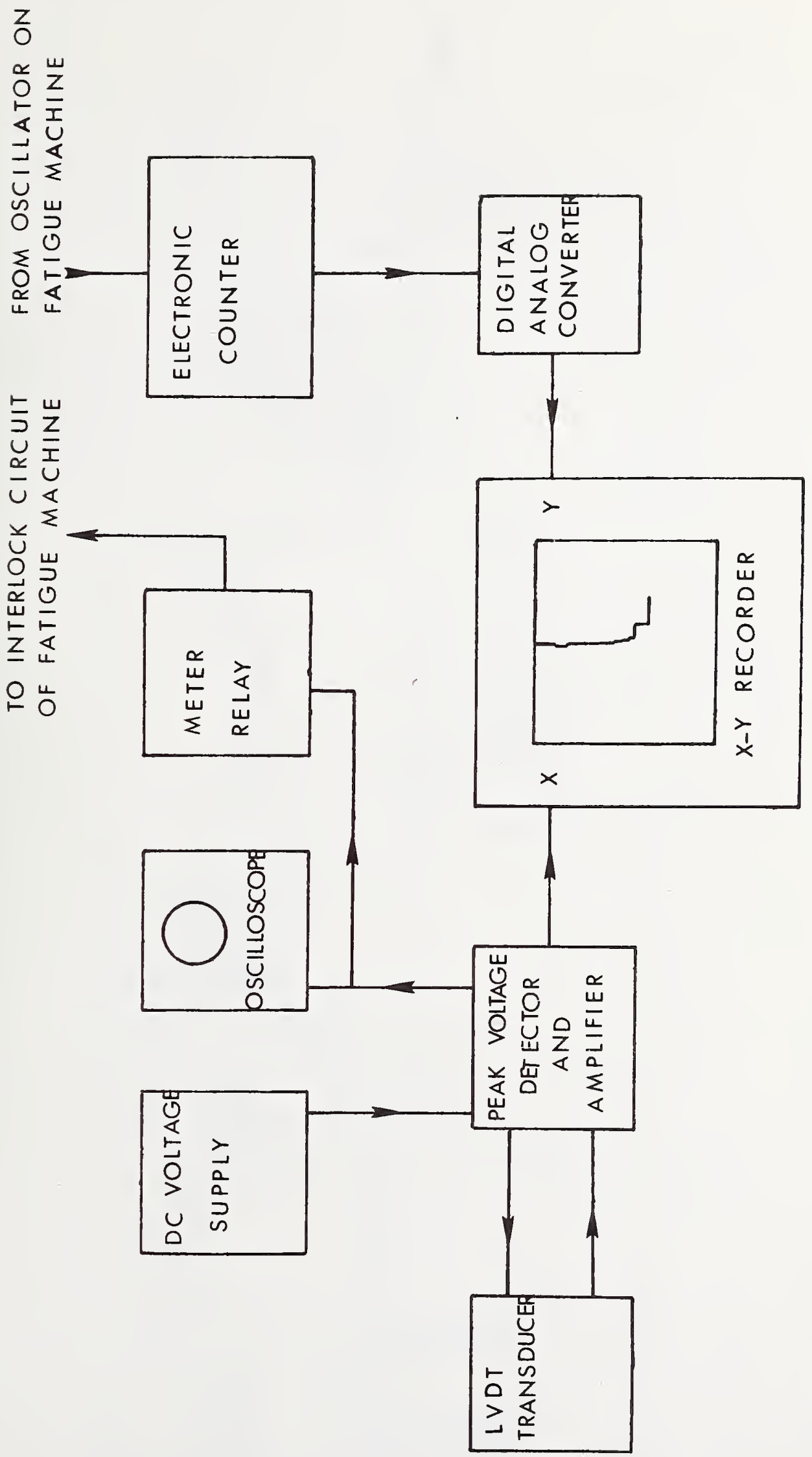

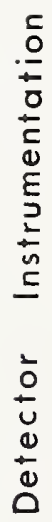

$\stackrel{5}{\circ}$

4

$\frac{E}{0}$
$\frac{1}{0}$
$\frac{0}{0}$
$\frac{0}{u}$
$\frac{0}{\infty}$
1
0
0
$\frac{1}{5}$
은 


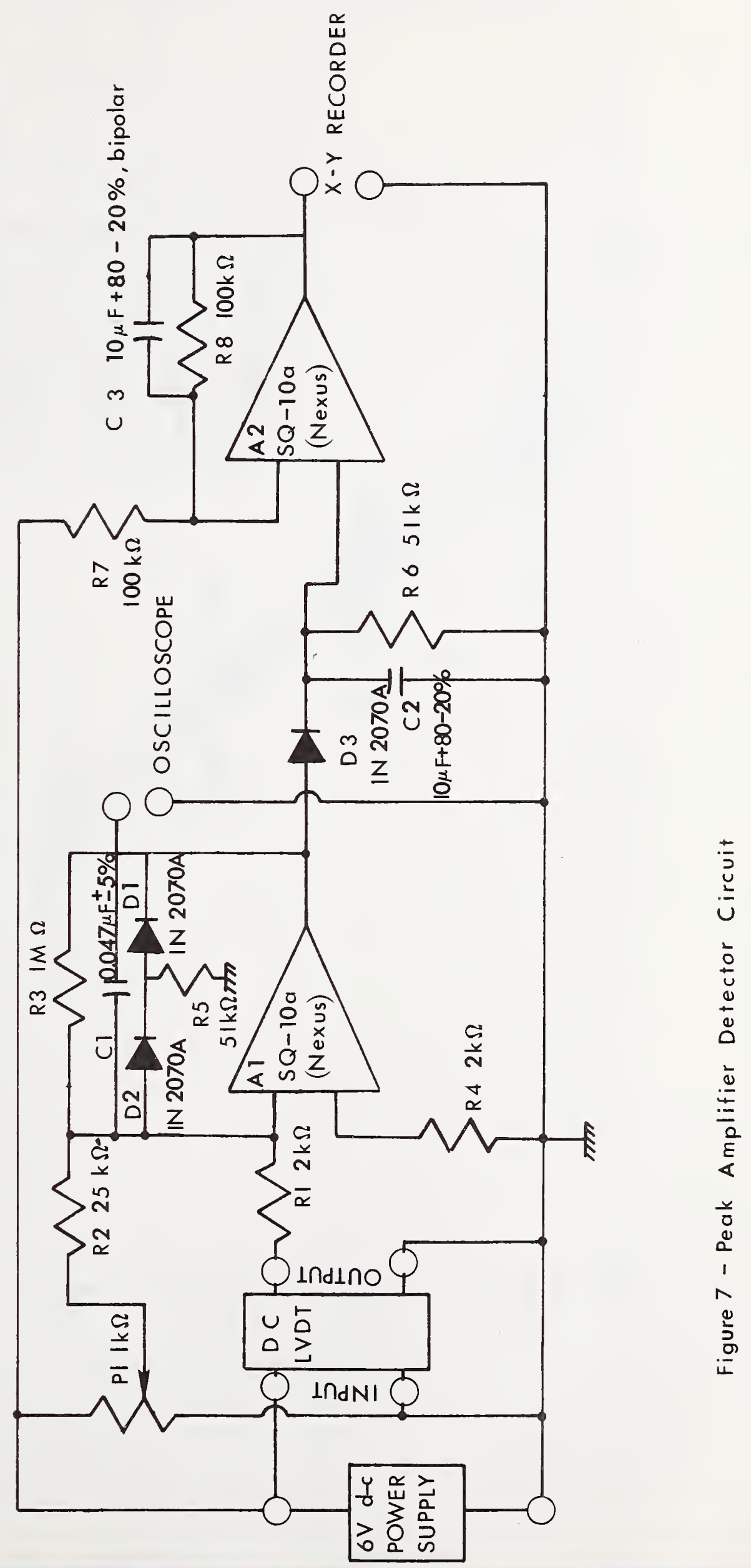




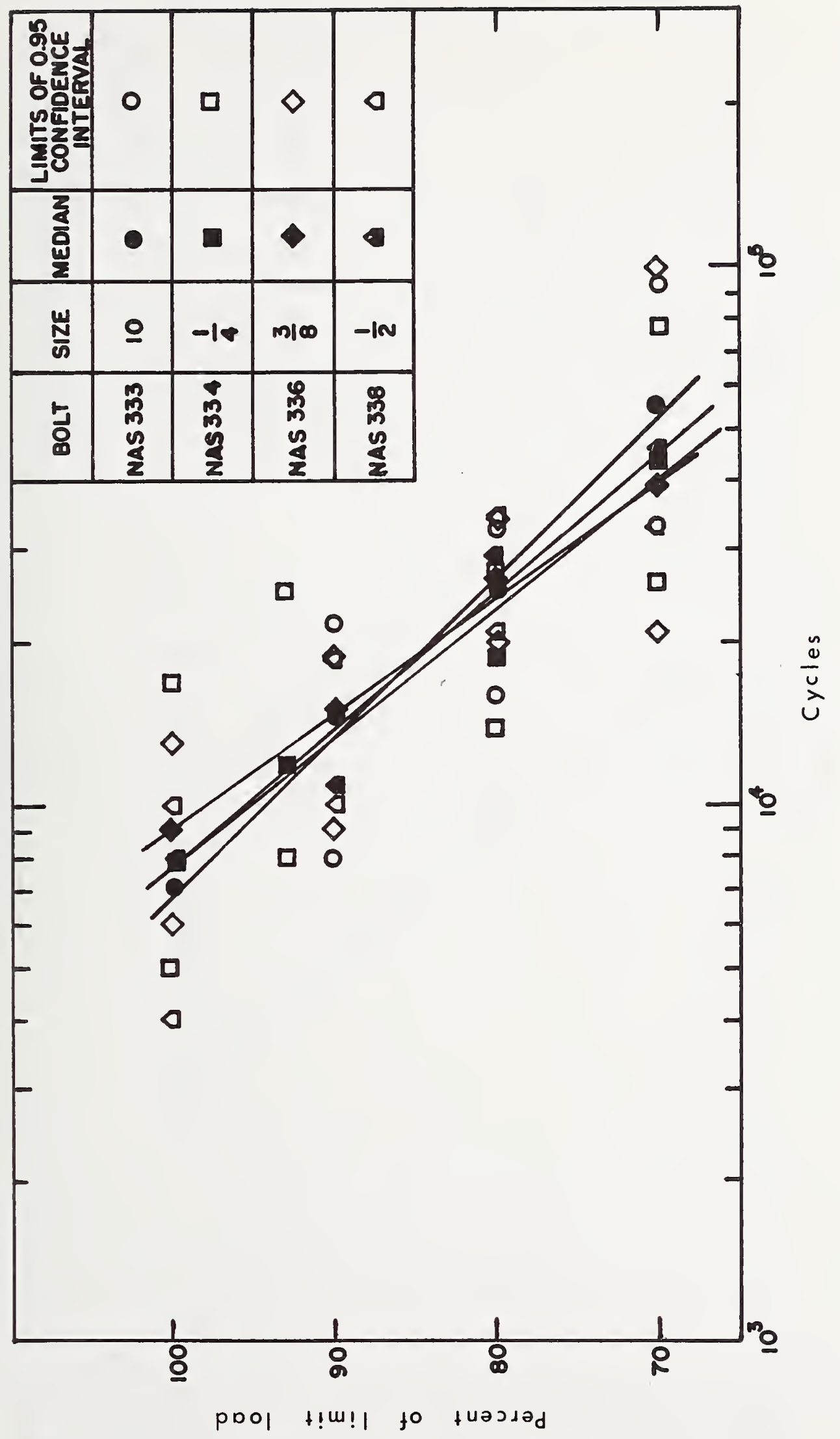

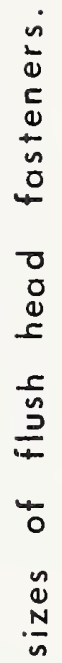

$\frac{1}{3}$

4

$\stackrel{n}{0}$

$\frac{2}{2}$

1
0
0
$\frac{1}{n}$
1
1
$\frac{1}{0}$
0
0

$\frac{1}{0}$

$\infty$

$\frac{1}{3}$
0
$\frac{1}{4}$ 


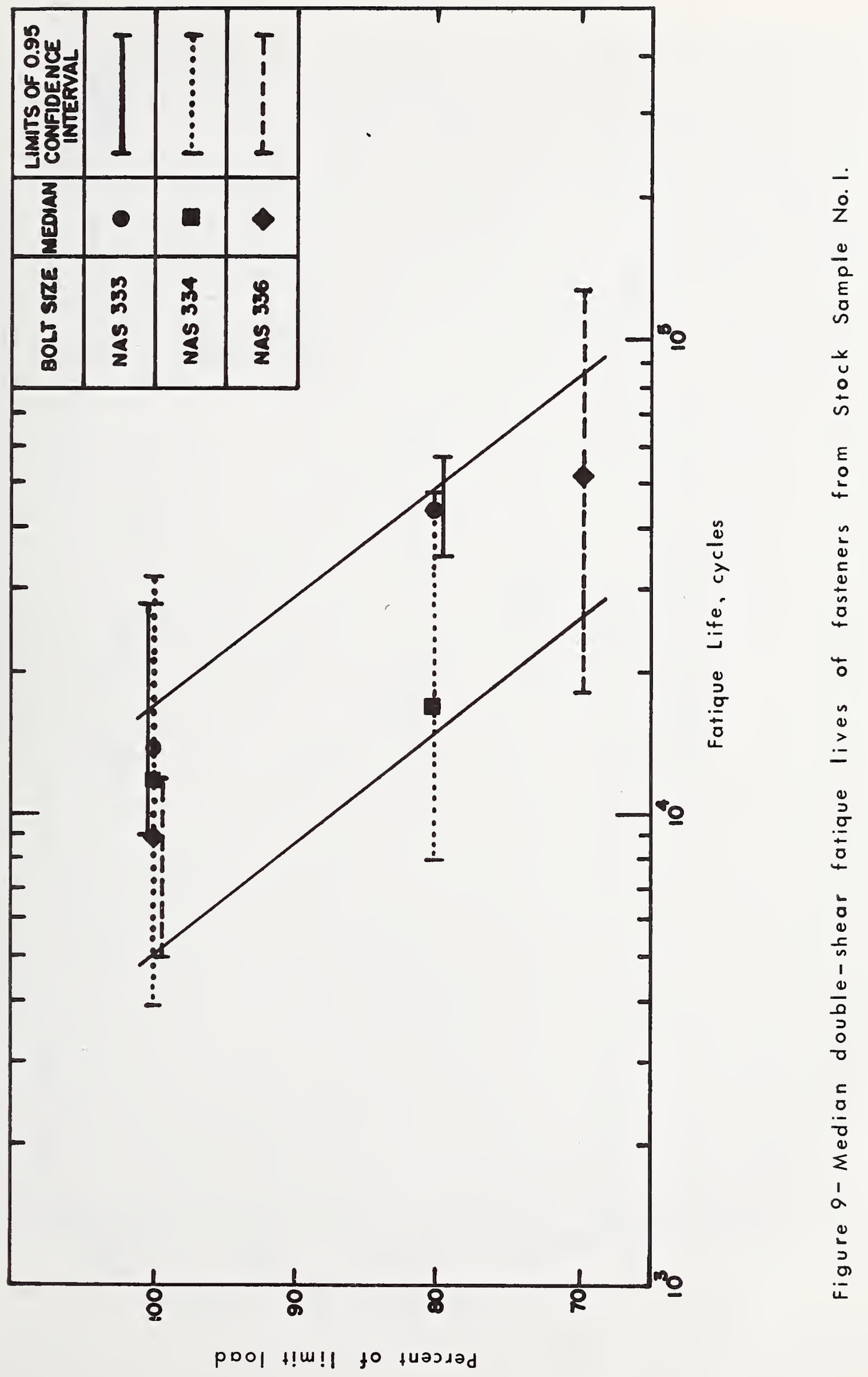




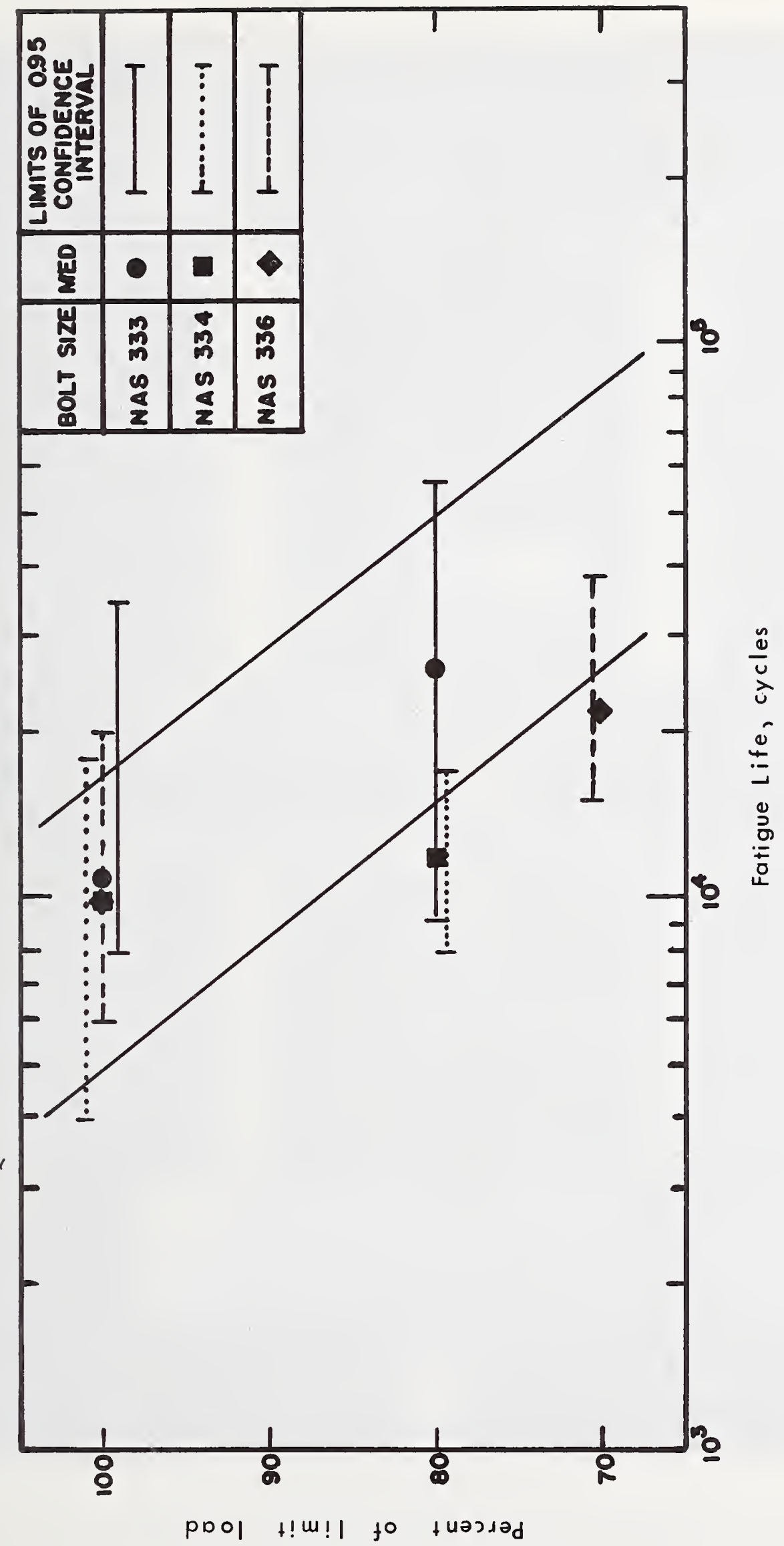

$\stackrel{\dot{\sim}}{\dot{0}}$

$\frac{0}{0}$
E
0
n

$\frac{y}{u}$

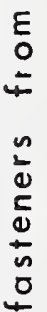

4

$\stackrel{0}{\geq}$

$\frac{0}{2}$

$\frac{1}{0}$
0
$\frac{1}{n}$
1
$\frac{0}{2}$
$\frac{0}{2}$
$\frac{0}{0}$

$\frac{5}{0}$
$\frac{0}{0}$
0
1
0
0

ำ

PDOI t!m!I to tuəssəd 



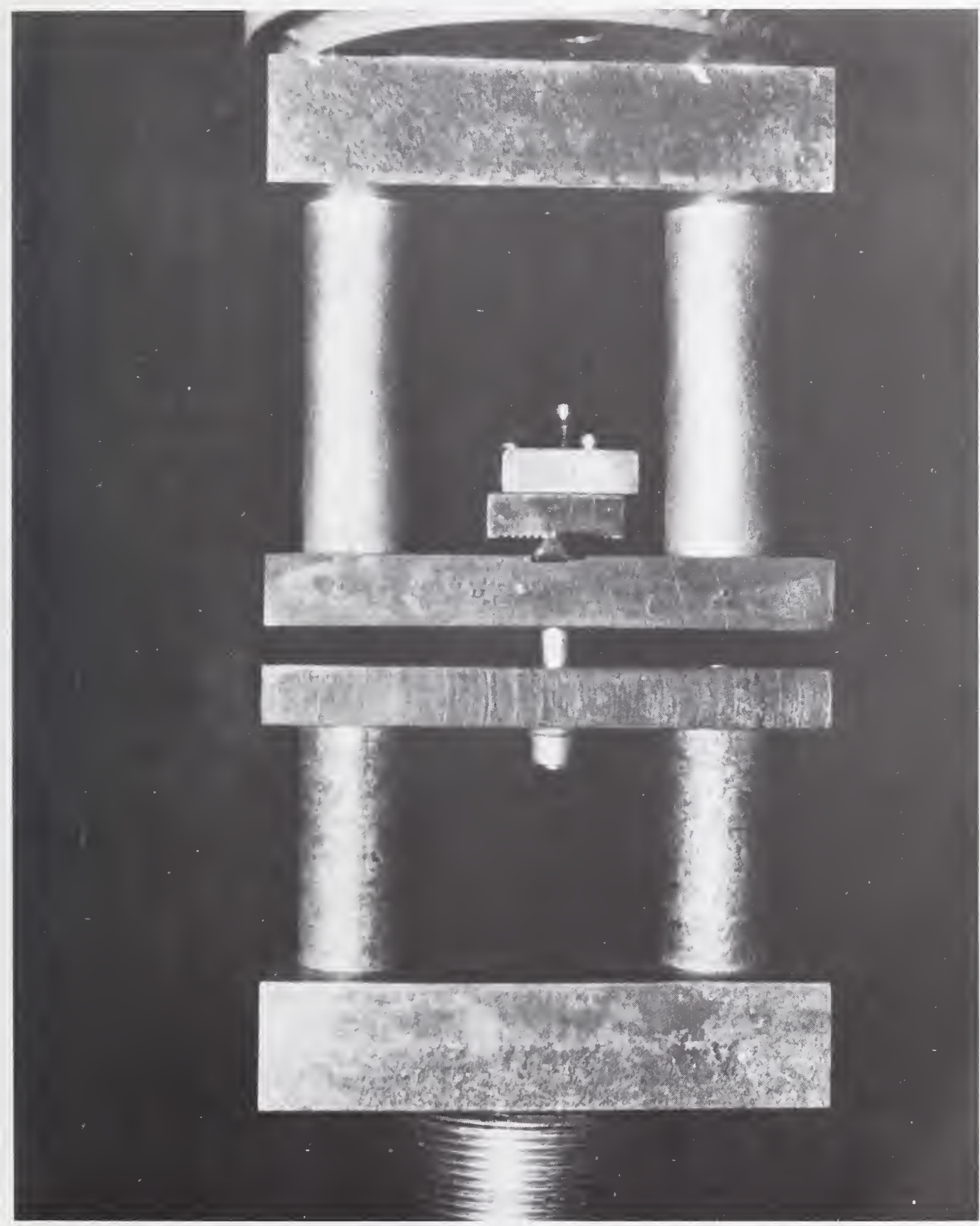

Figure 11 - Tension-bending fatigue test fixtures 



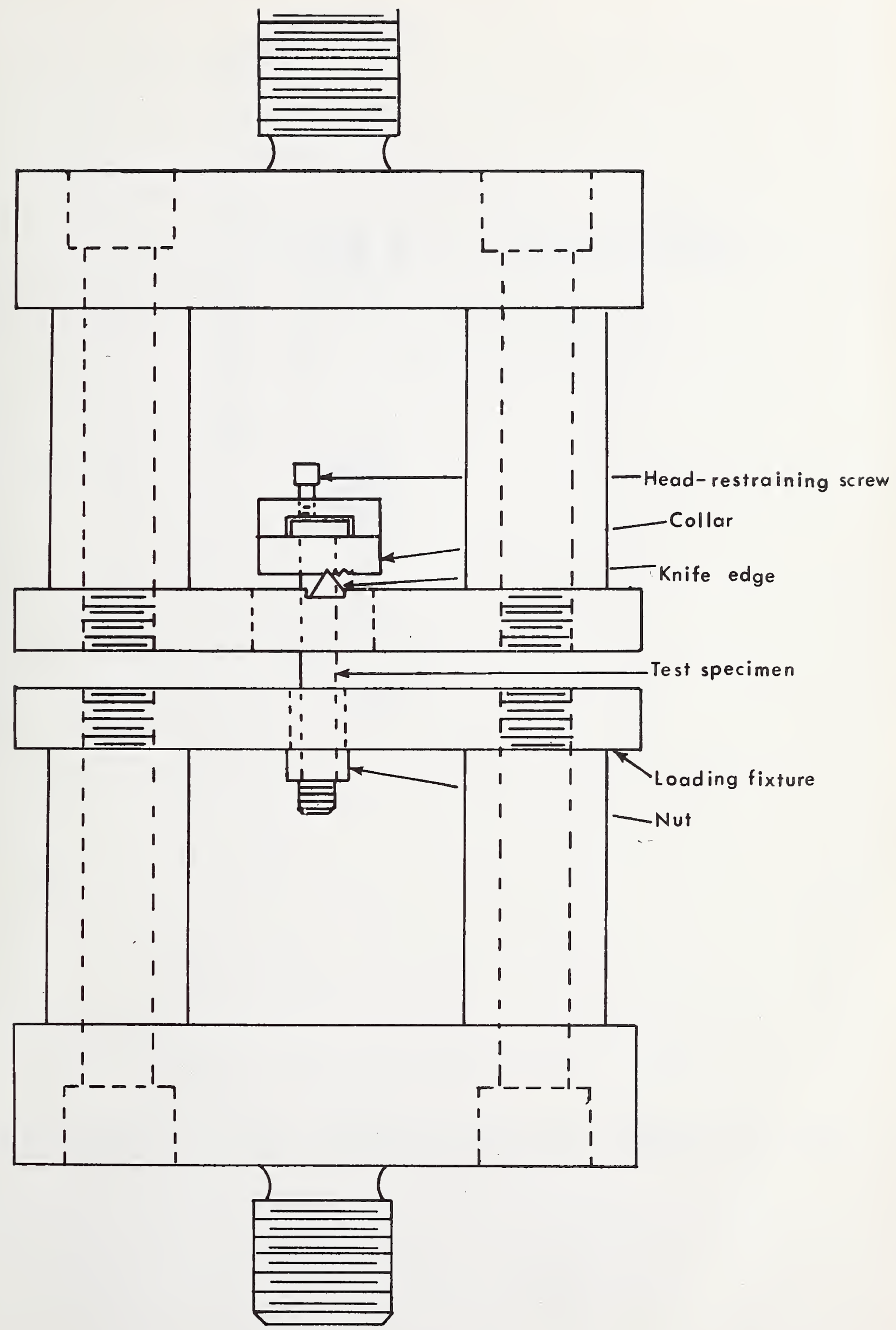

Figure 12 Schematic of tension-bending fatigue test fixtures. 

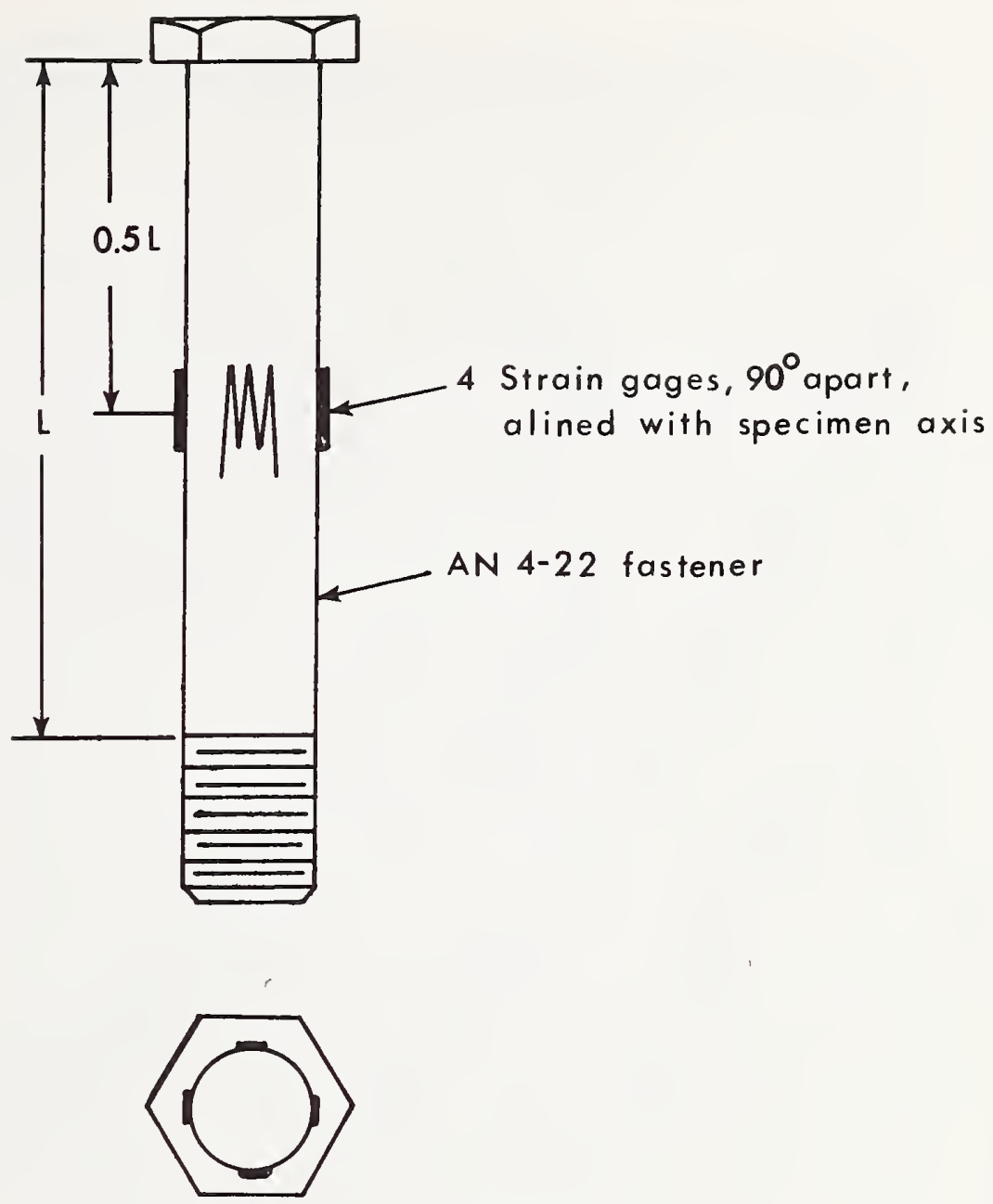

Figure 13 - Bending measurement device used with tension-bending test fixtures. 

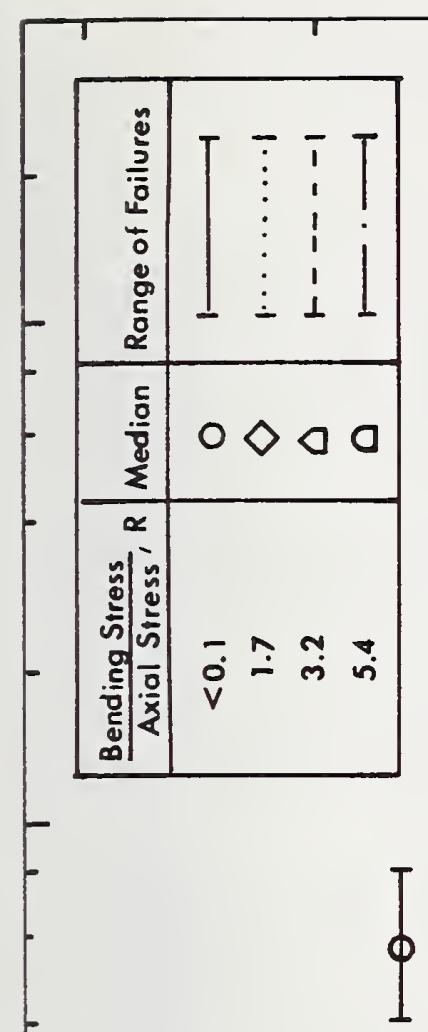


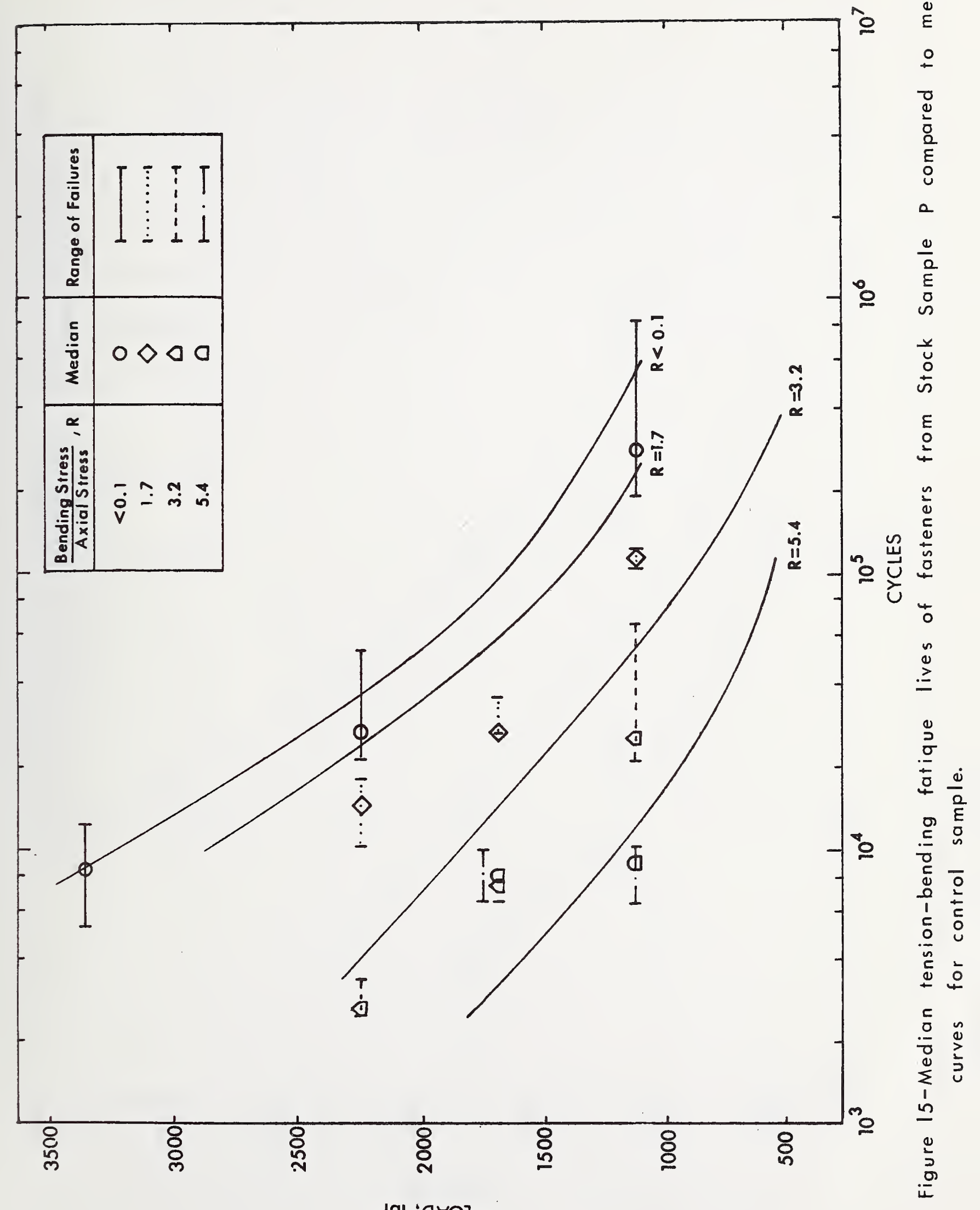

$f 9 l^{\circ} \mathrm{a \forall 07}$ 


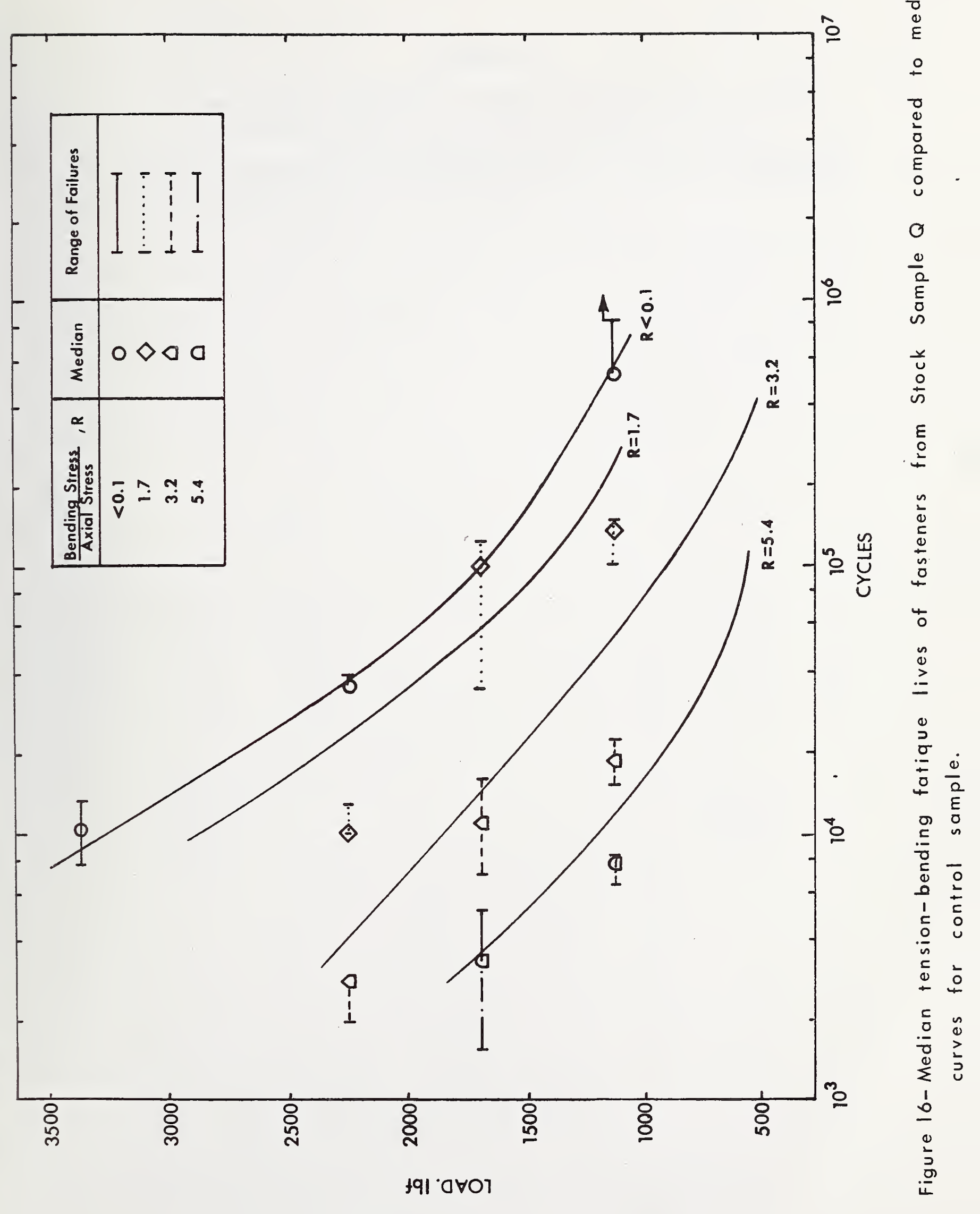





\section{APPENDIX AI}

Double Shear Fatigue Test Fixtures for 0.190 (No. 10) and

0.250-in Flush Head Threaded Airframe Fasteners

Detailed drawings for the fixtures used for the tests described in this paper are given in figures Al to A7. 

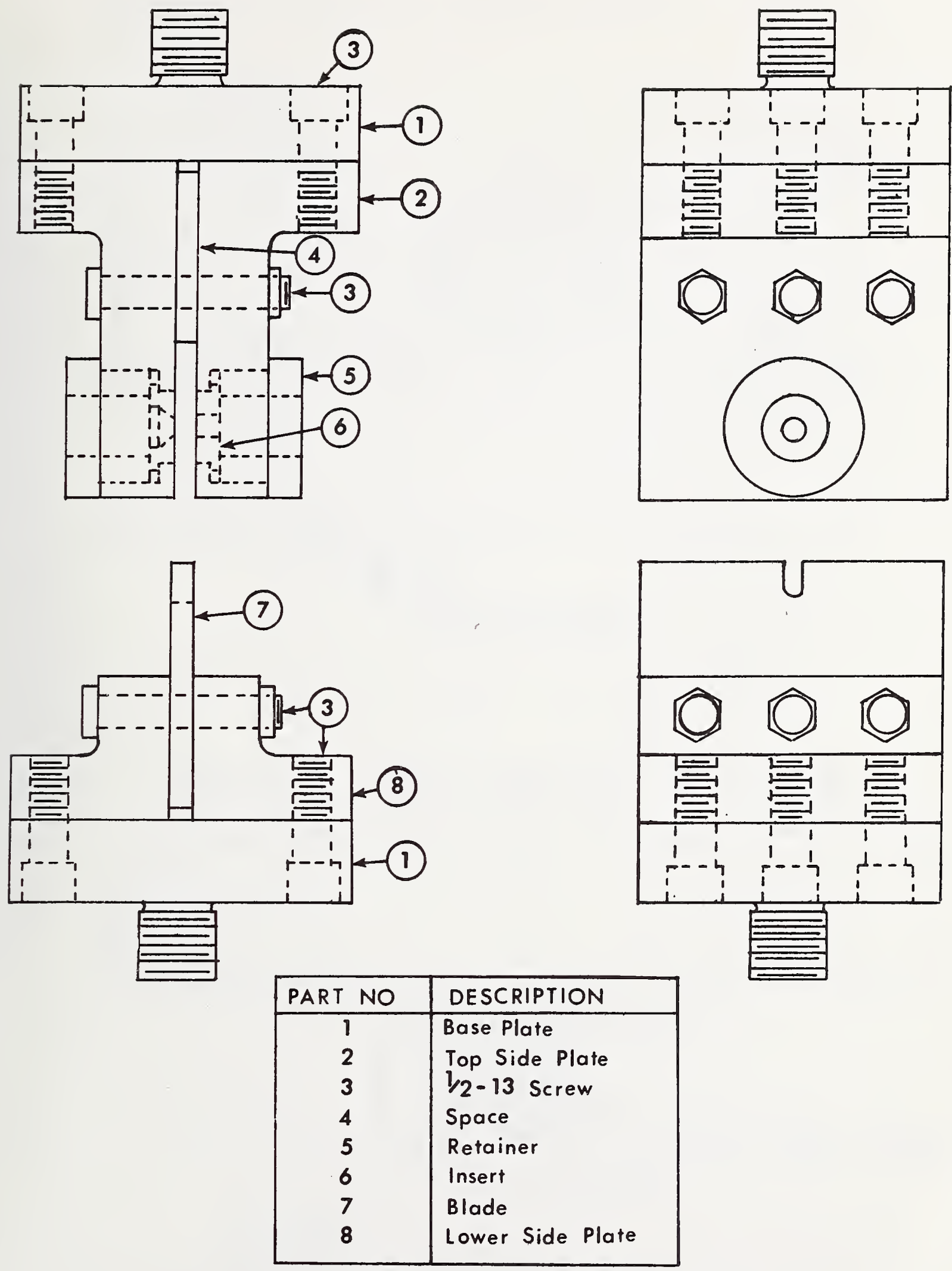

Fig. Al-Double Shear Fixtures (10 and $\frac{1}{4}$ in fasteners), Assembly 


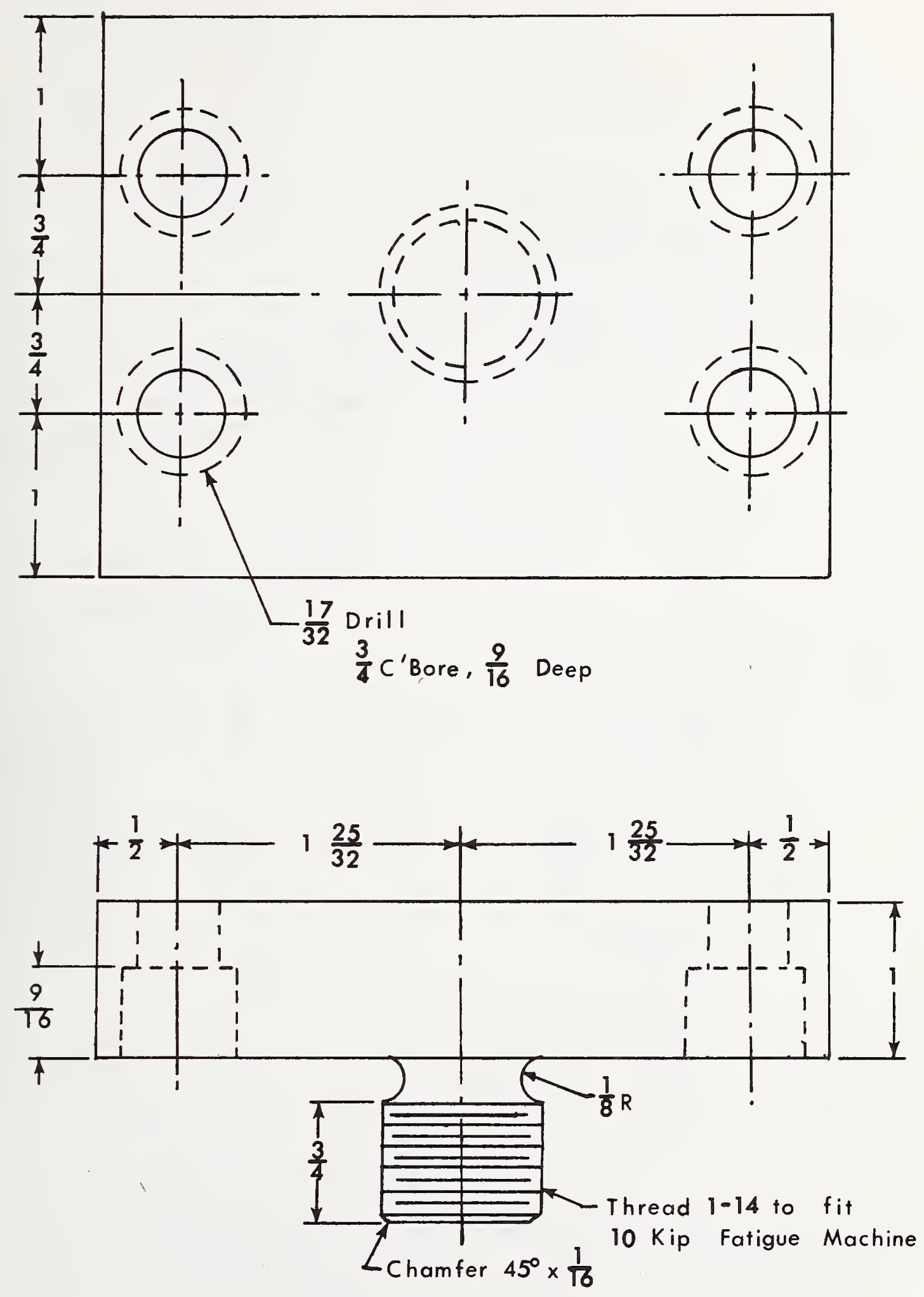

Part No. 1

Base Plate

Material: 0-2 Tool Steel $R_{c} 60$

2 Required

Fig. A 2 



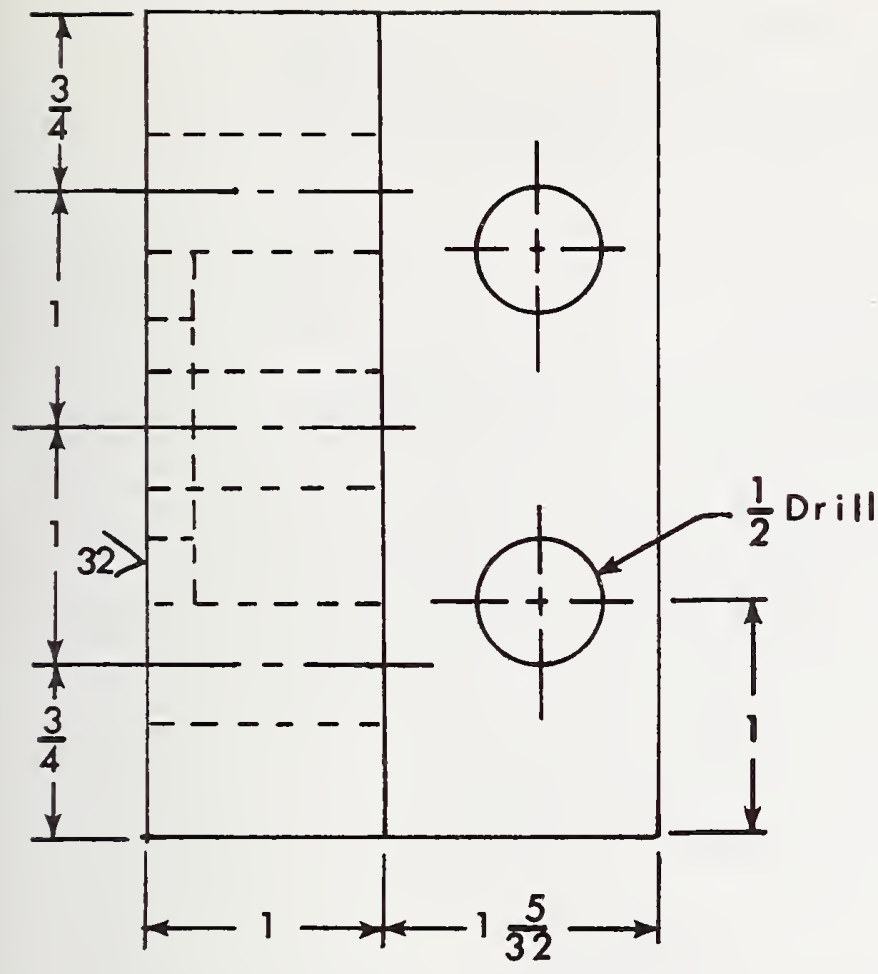

Part No. 2

Top Side Plate

Material: 0-2 Tool Steel

$R_{c} 60$

Grind Flat and $90^{\circ}$ after Heat Treating 2 Required

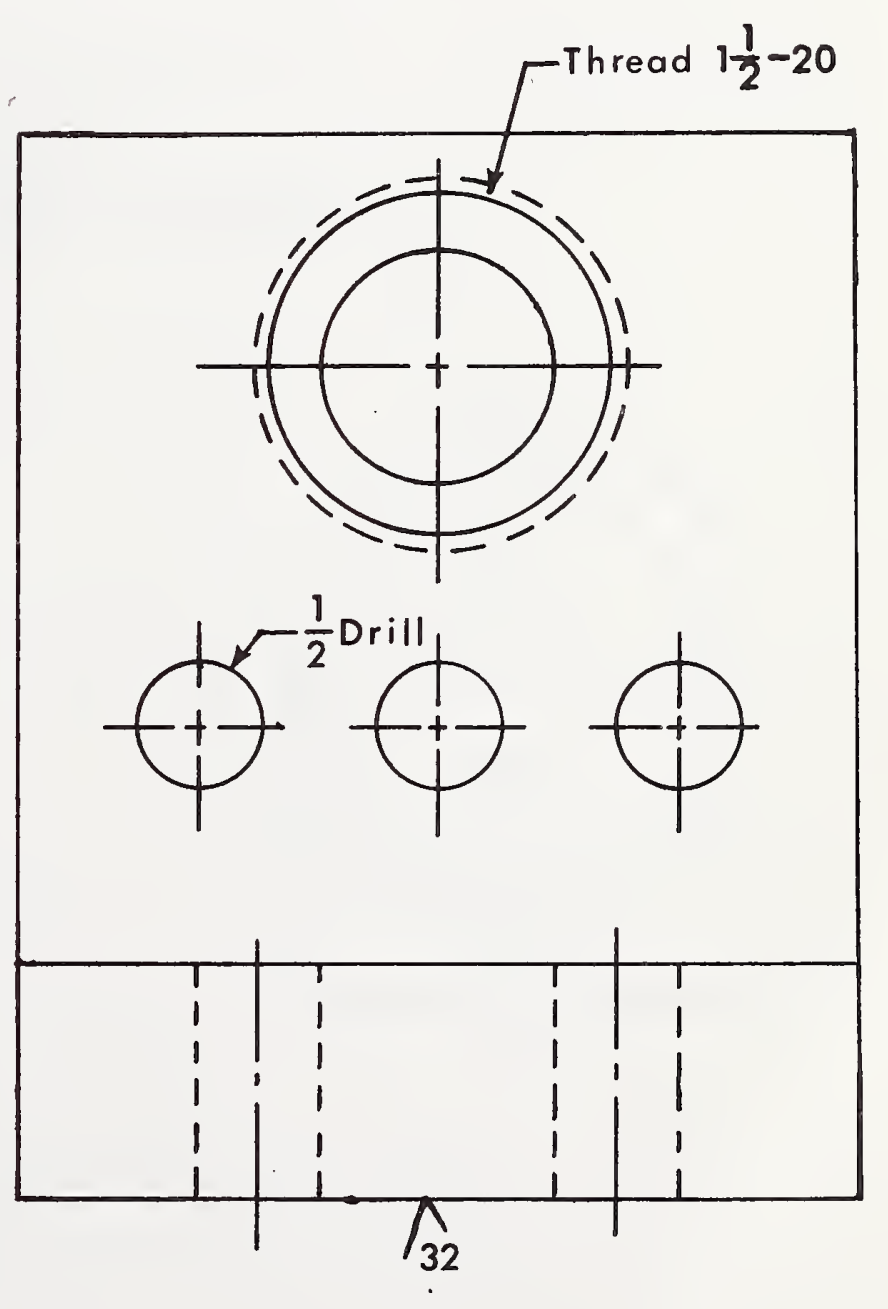

Fig. A 3 



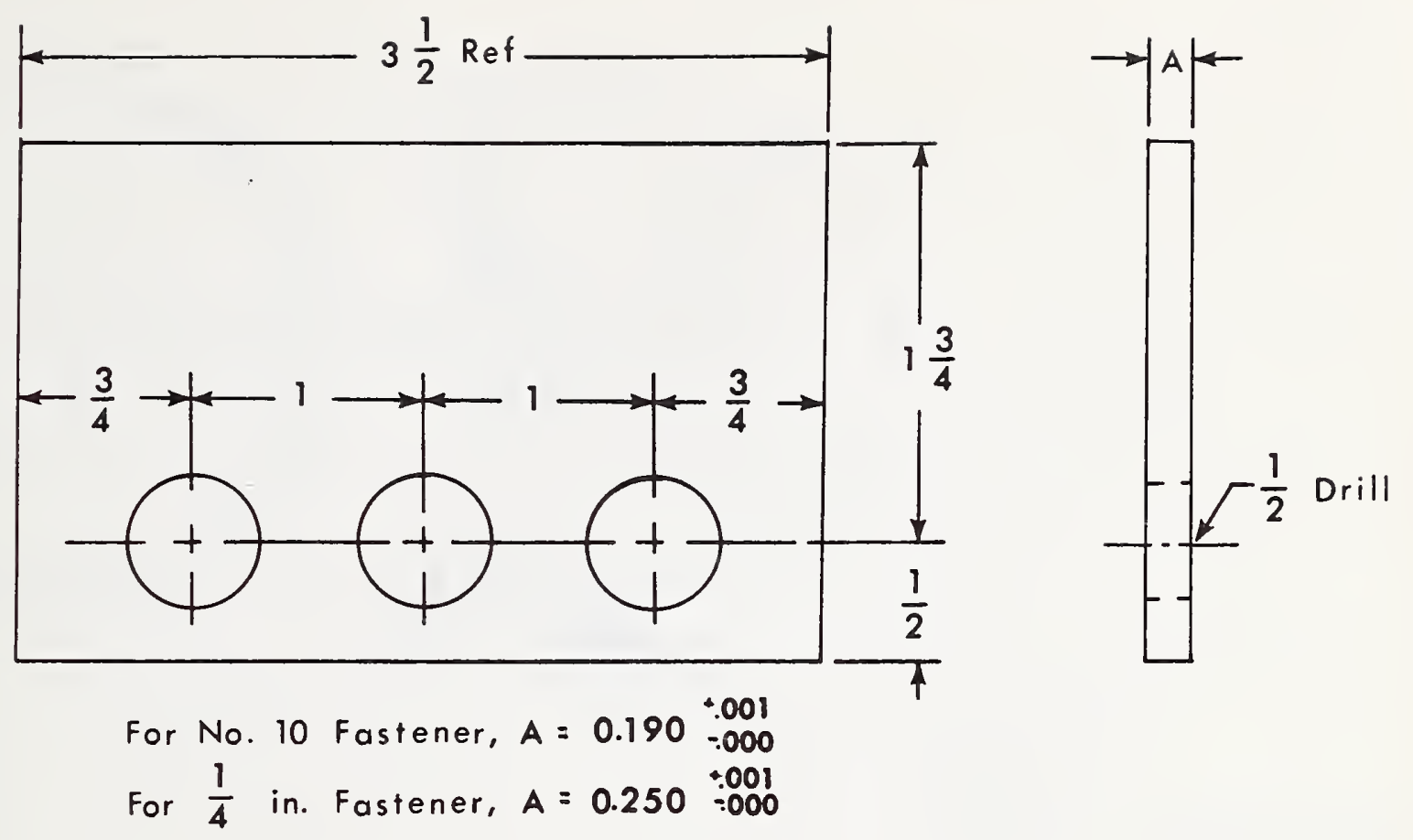

Part No. 4

Spacer

Material: 0-2 Toól Steel

$R_{c} 60$

1 Required for each size fastener
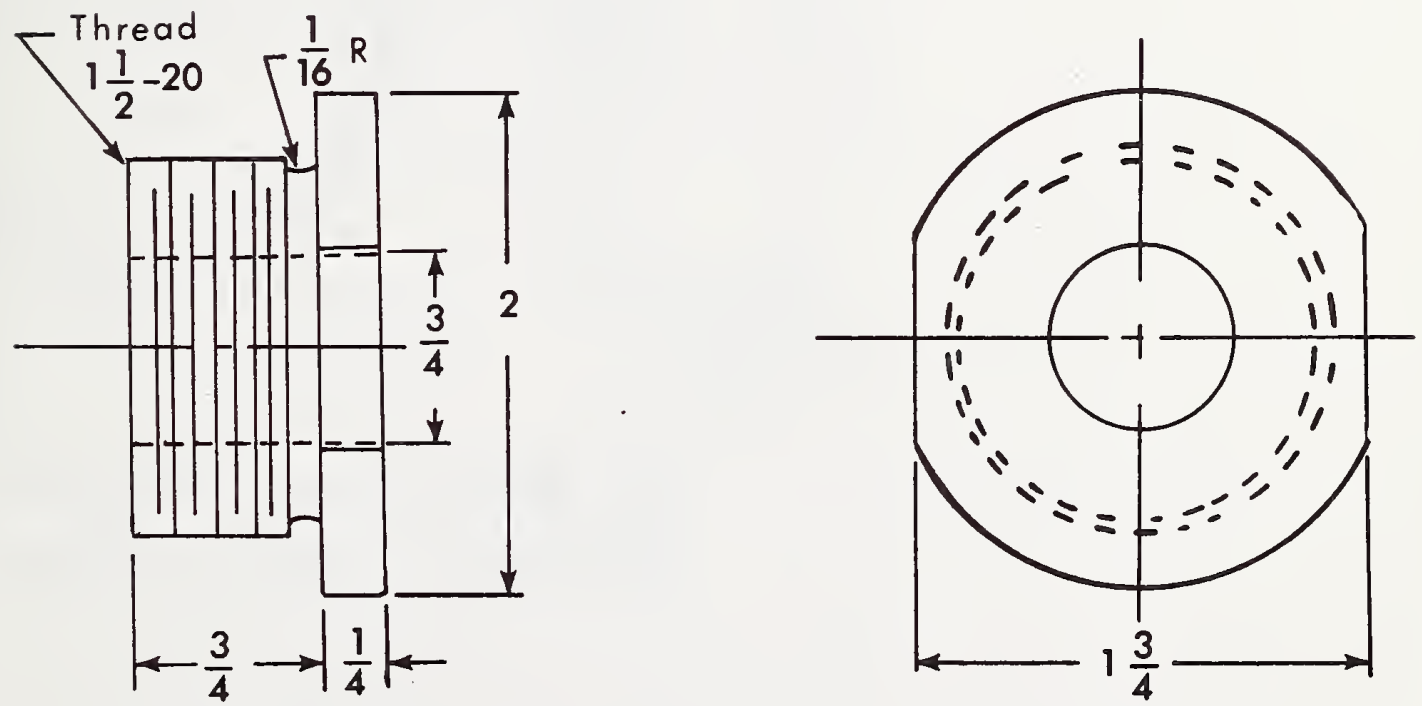

Part No. 5

Retainer

Material: $2024-T 4$ Aluminum Alloy

2 Required

Fig. A4 


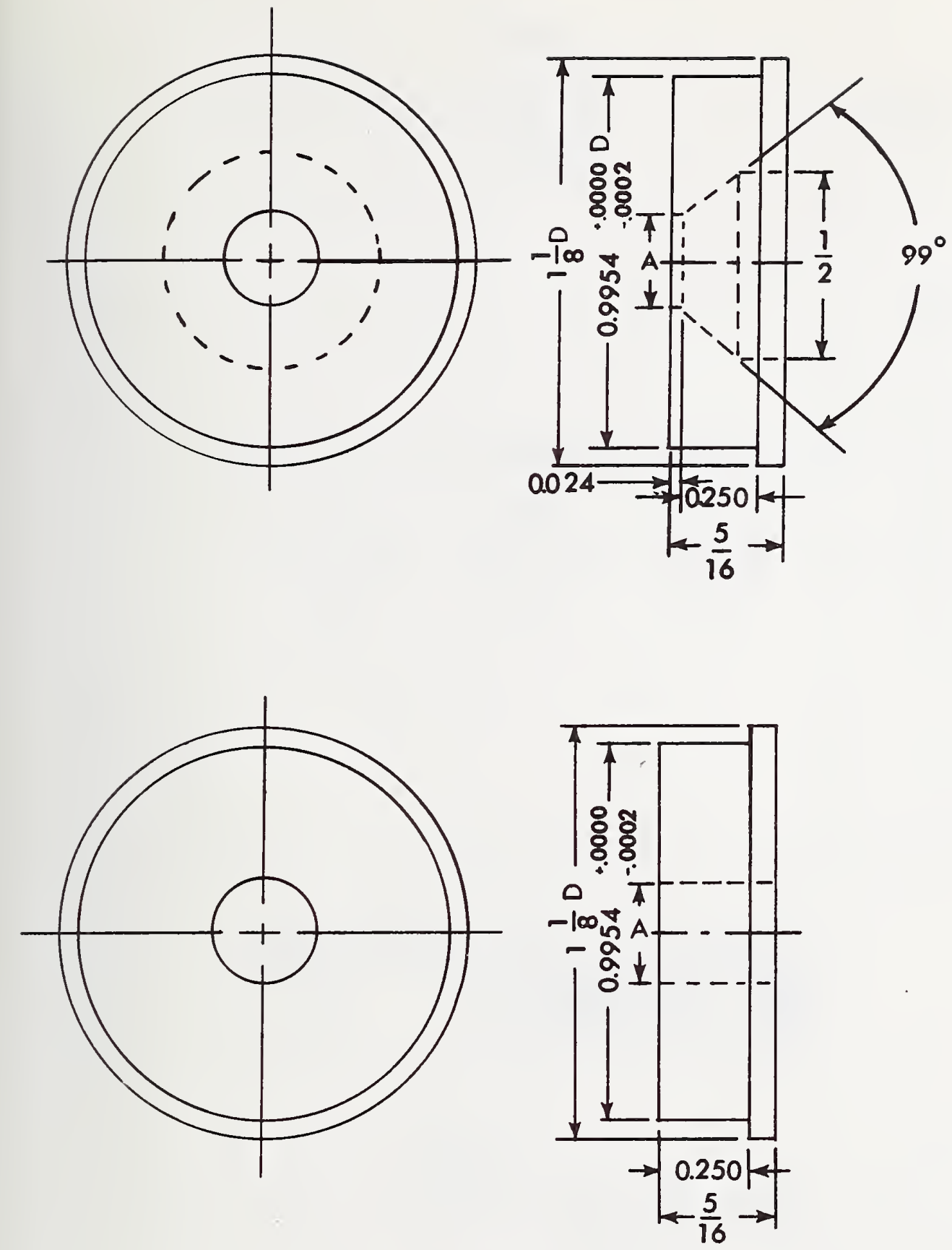

For No. 10 Fastener, $A=0.200 \stackrel{+000}{-.001}$

For $\frac{1}{4}$ in. Fastener, $A=0.260_{-.001}^{+000}$
Part No. 6

Inserts

Material: AISI 4340 Steel $R_{c}$ 45-50

1 Each Required for each size fastener 



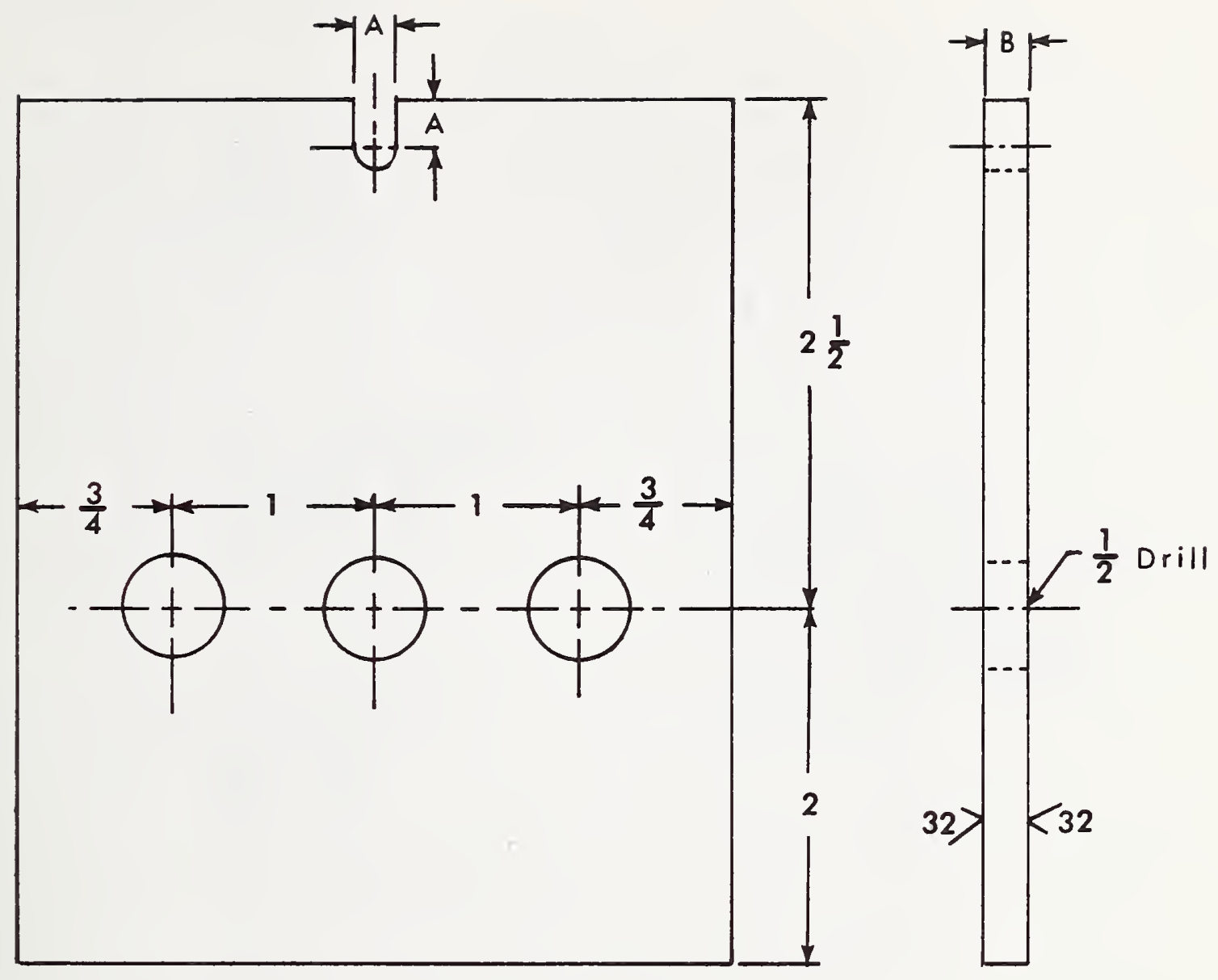

\begin{tabular}{|c|c|c|}
\hline Fastener Size & $A$ & $B$ \\
\hline $\mathrm{No}_{\frac{1}{4}} 10$ & $\begin{array}{l}0.190+001 \\
0.250+000 \\
0.001\end{array}$ & $\begin{array}{ll}0.188 & +.000 \\
0.249 & +000 \\
0.001\end{array}$ \\
\hline
\end{tabular}

\footnotetext{
Pait No 7

Blade

Material: 0-2 Tool Steel

$R_{c} 60$

Grind Flat and Parallel after Heat Treating

1 Required for each size fastener
}

Fig. A6 


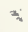

$3 i$

$\%$

$-4$

T.
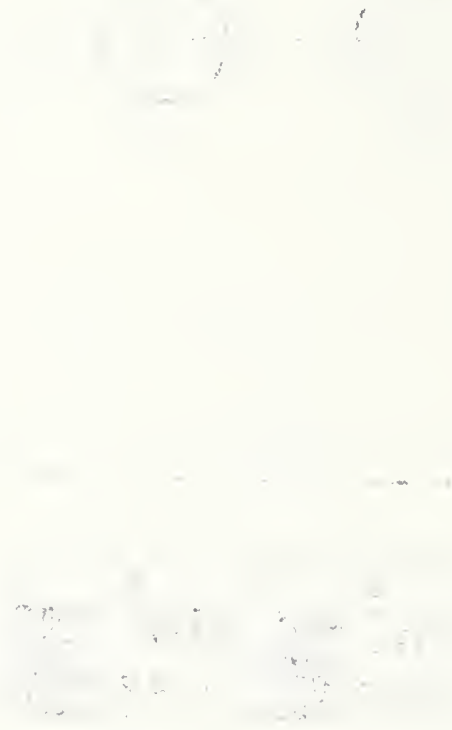

4 


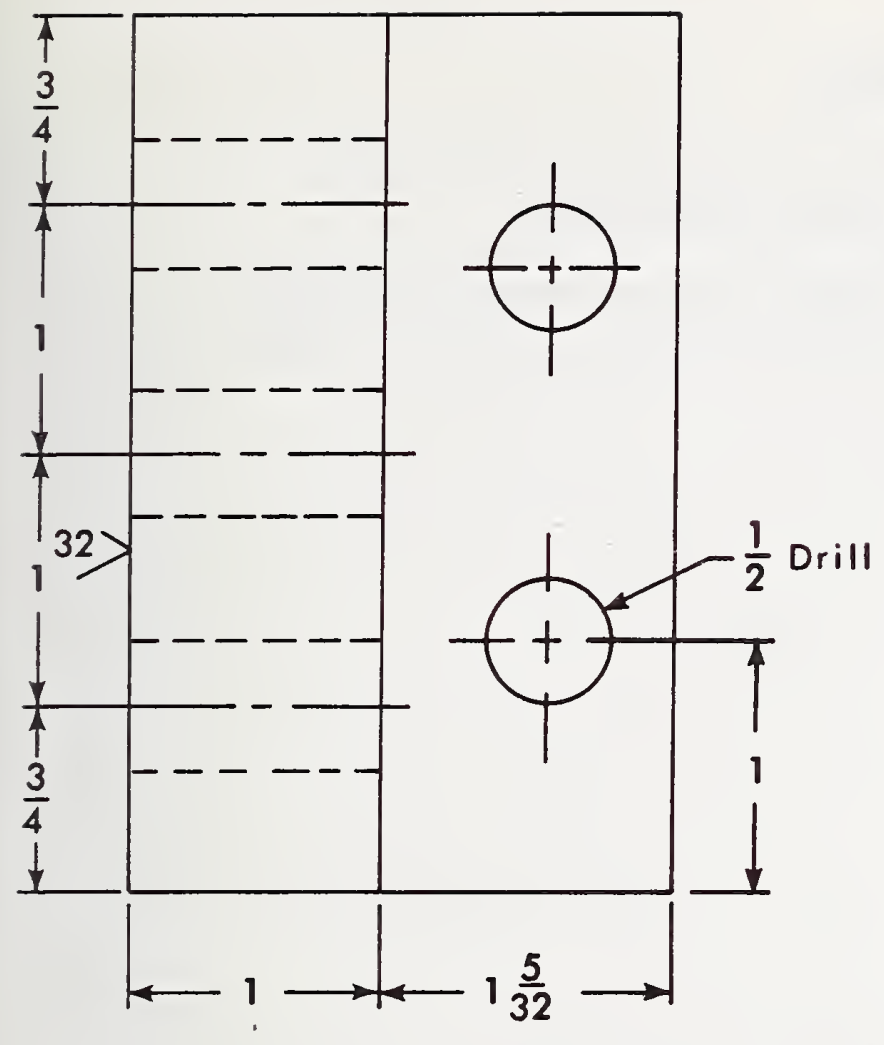

Part No. 8 Lower Side Plate Material: 0-2 Tool Steel $R_{c}-60$ Grind Flat and $90^{\circ}$ after heat treating 2 Required
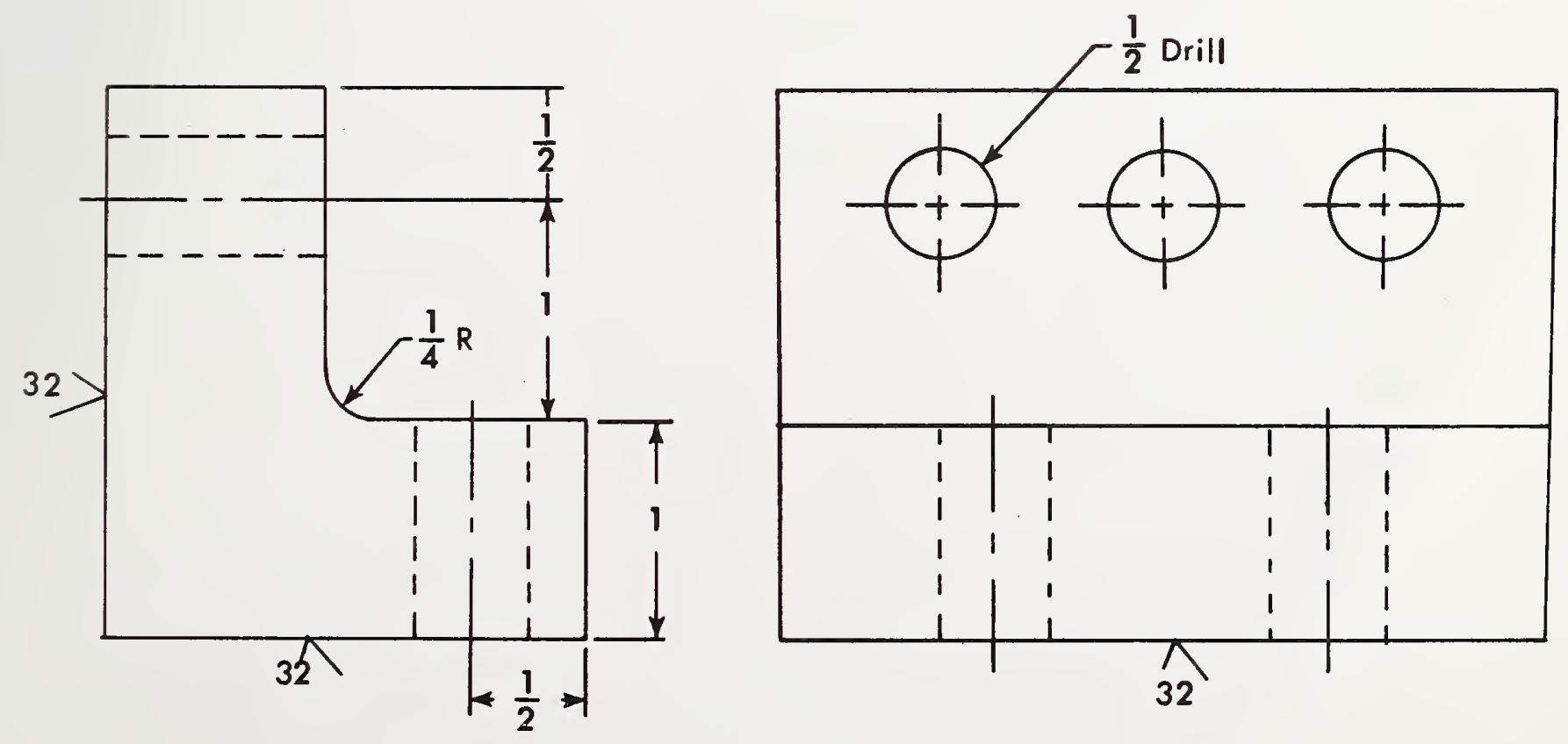

Fig. $A 7$ 



\section{APPENDIX A2}

Double Shear Fatigue Test Fixtures for 0.375 , and 0.500 -in Flush Head Threaded Airframe Fasteners

Detailed drawings for the fixtures used for the tests described in this paper are given in figures A8 to A17. 
$\therefore \quad \therefore$ 


\begin{tabular}{|c|l|}
\hline PART NO. & DESCRIPTION \\
\hline 1 & Base Plate \\
2 & Top Side Plate \\
3 & l/2-13UNC-2 Screw \\
4 & Spacer \\
5 & Retainer \\
6 & Insert \\
7 & Blade \\
8 & Lower Side Plate \\
\hline
\end{tabular}
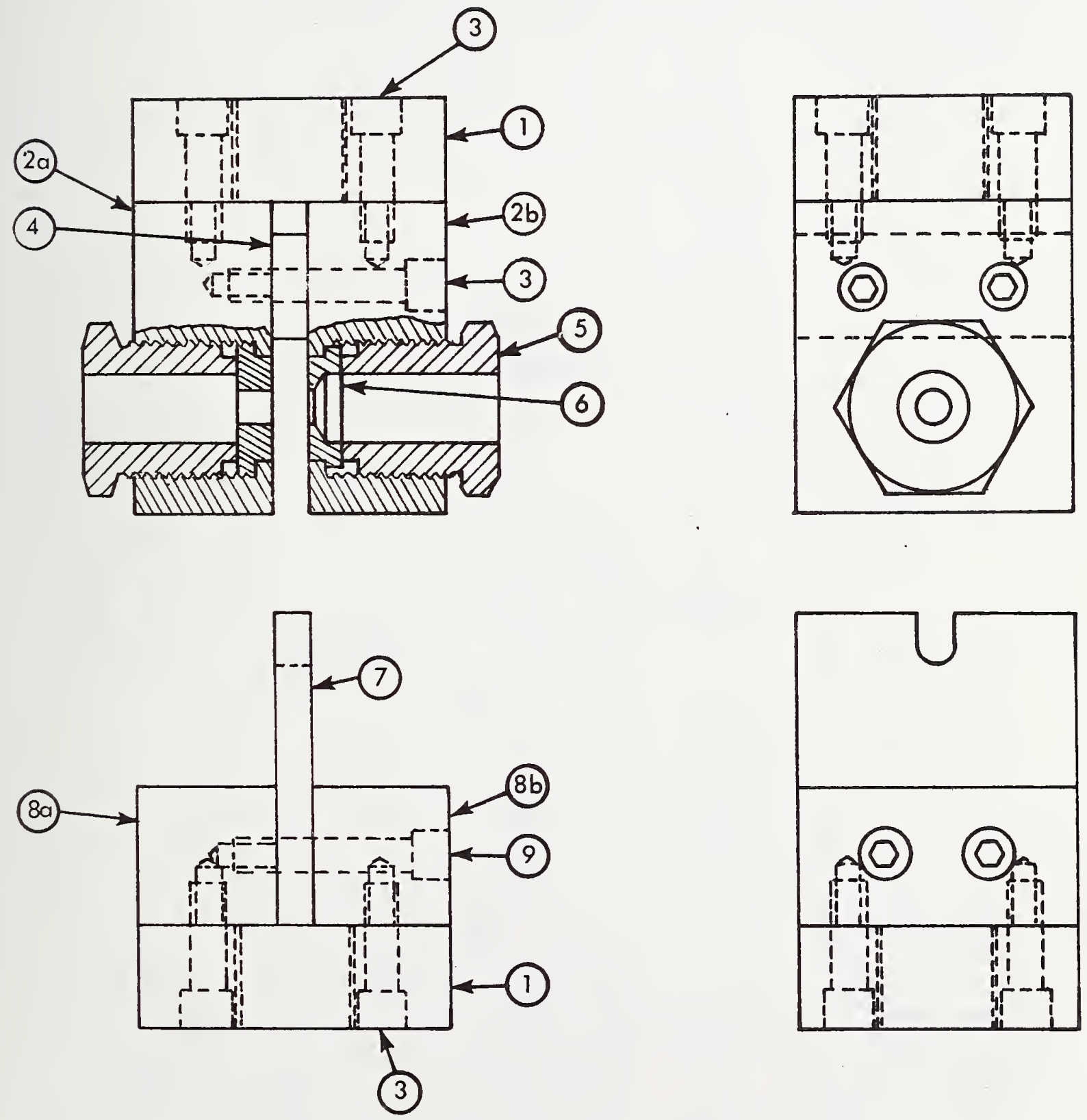

Fig. A8 - Double Shear Fixtures ( $3 / 8$ and $\frac{1}{2}$ in fasteners), Assembly 


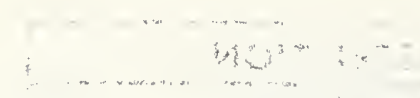

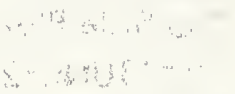

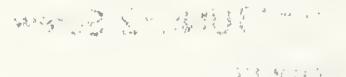

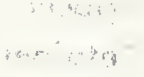

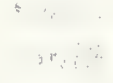$$
5
$$

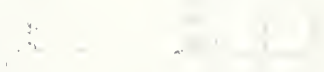$$
\text { is }
$$
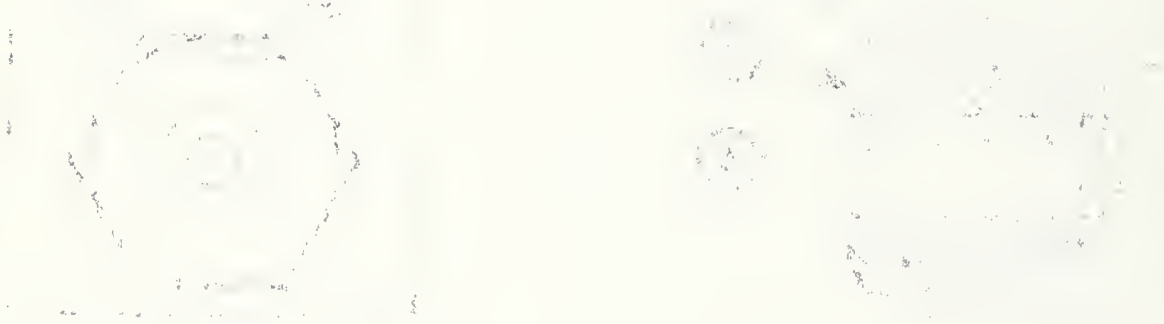


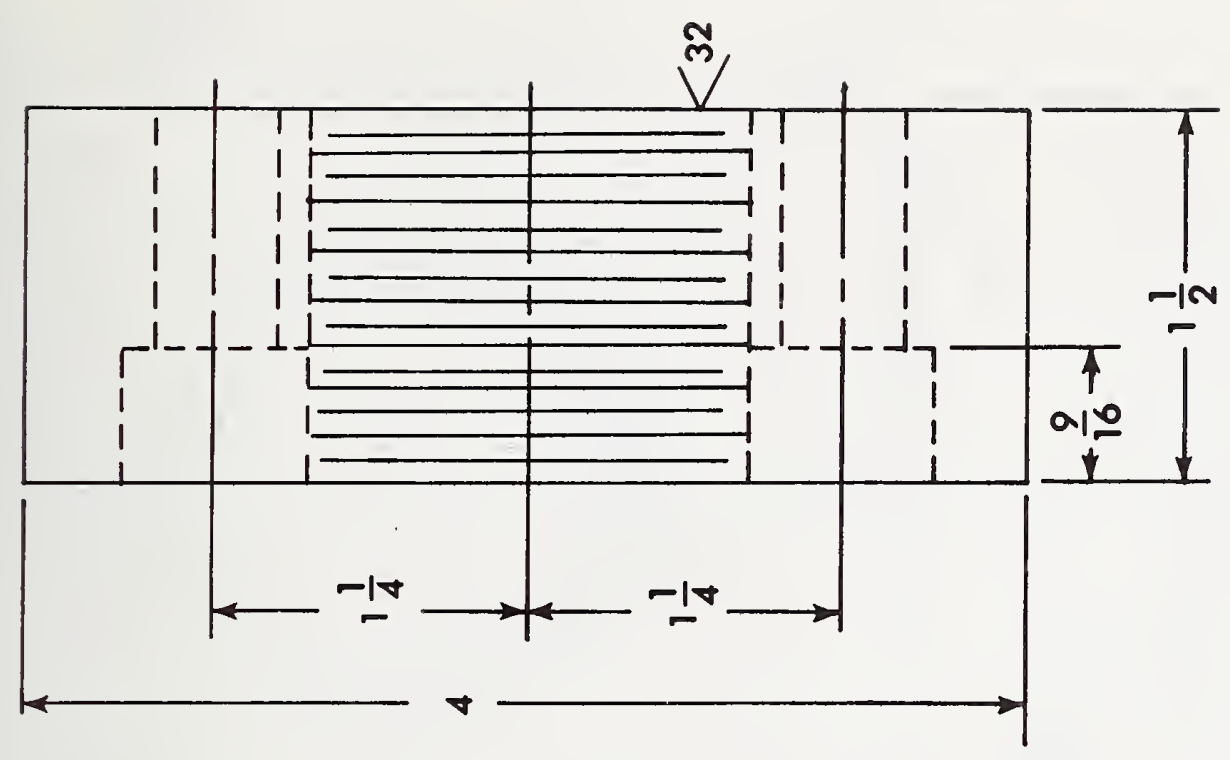

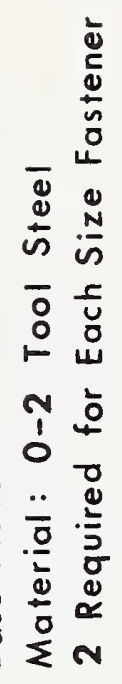

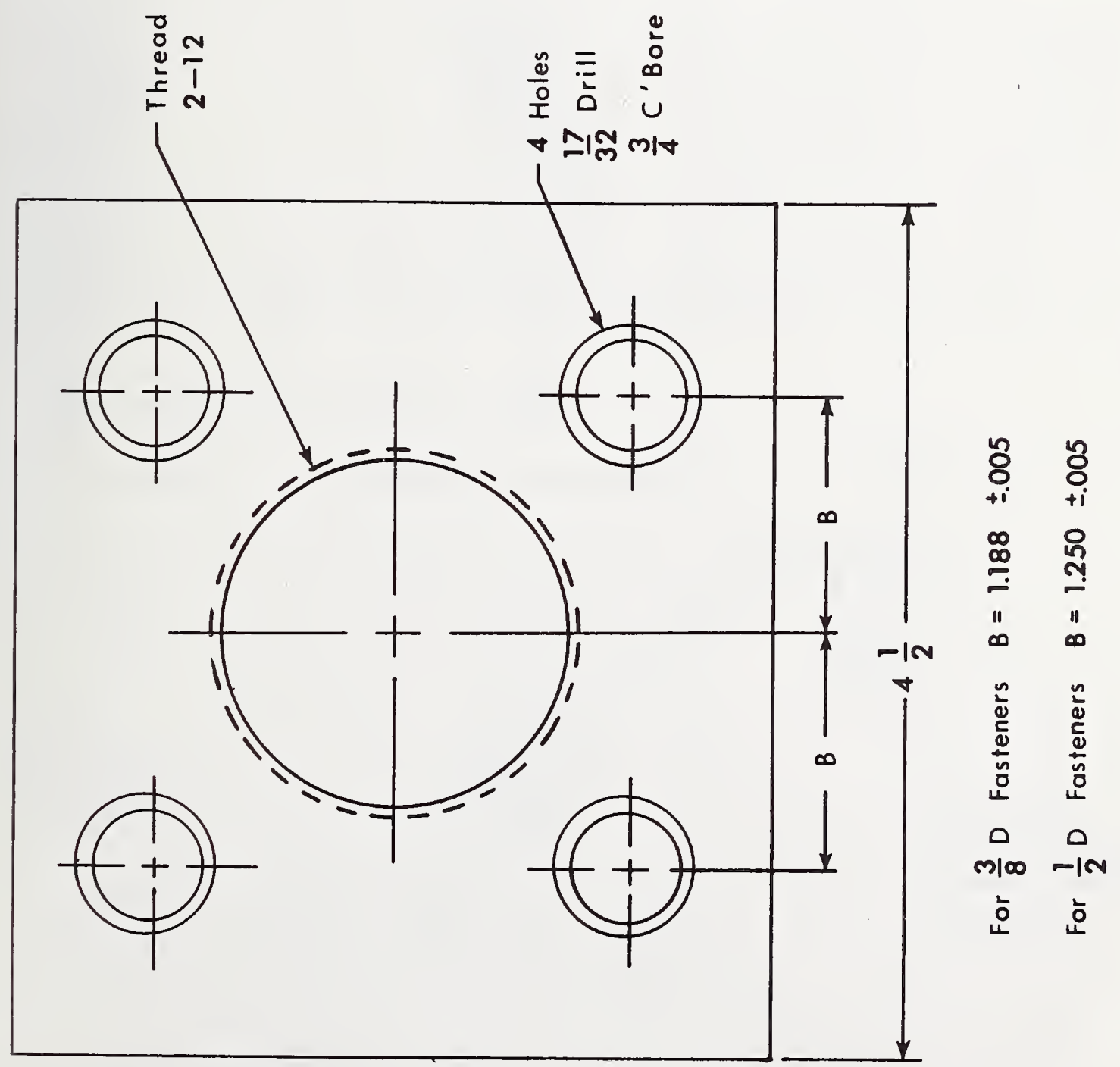

0
4
$\frac{1}{4}$ 



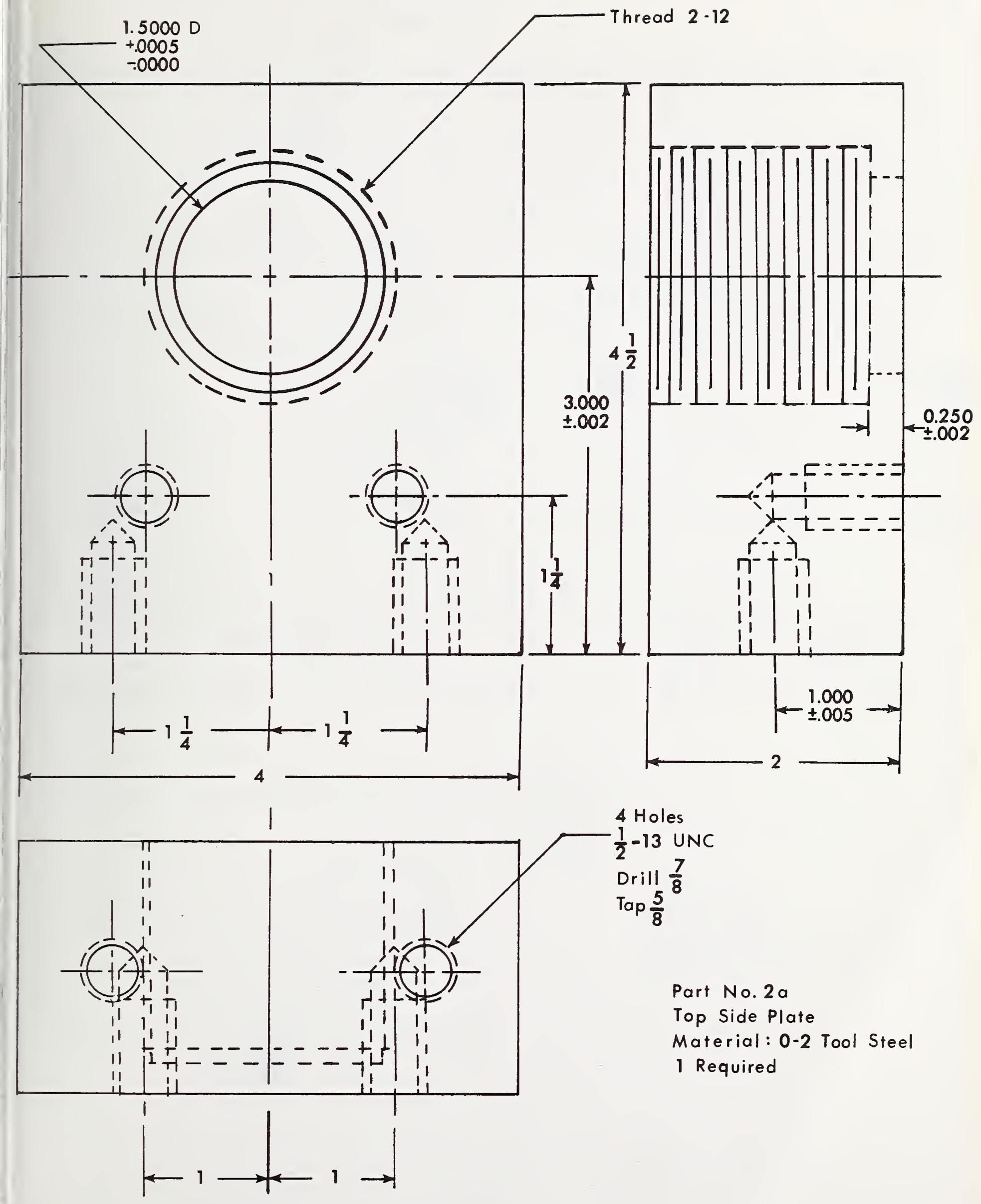

Fig. A 10 


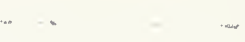





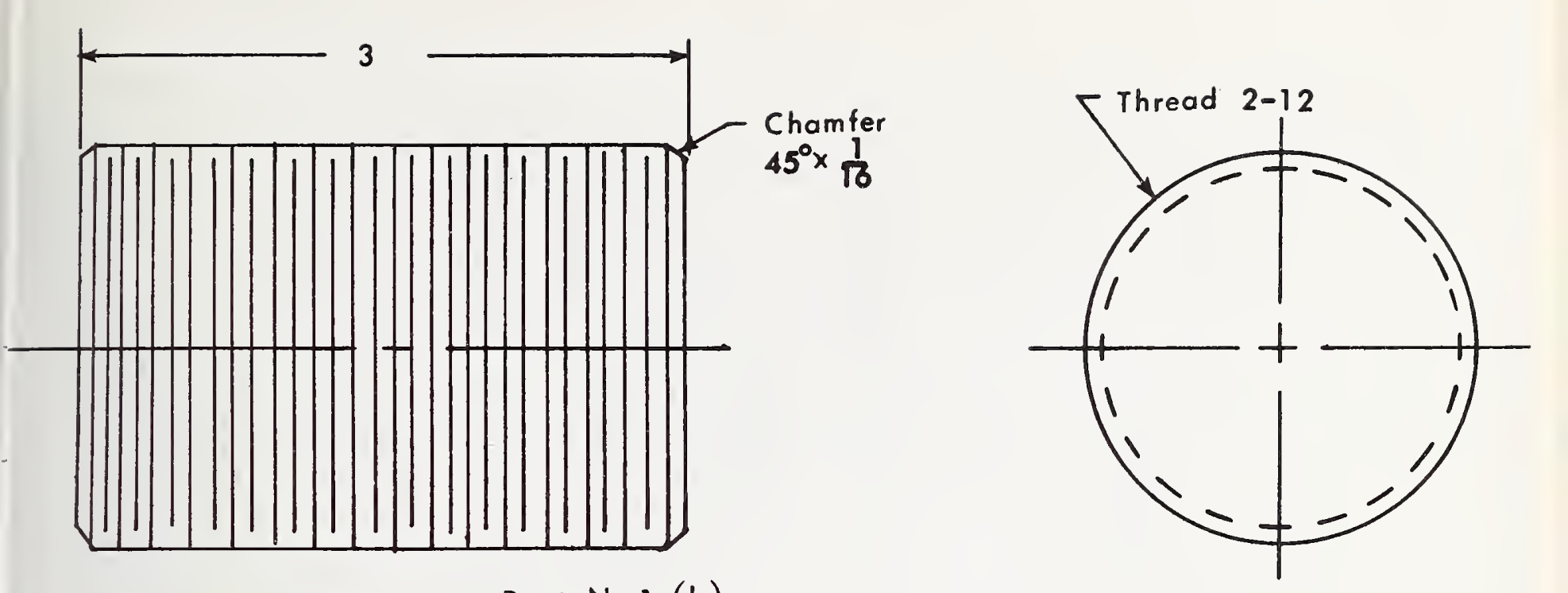

Part No 1 (b)

Stud

Material: A|SI 1015 Steel, Cold Drawn

2 Required
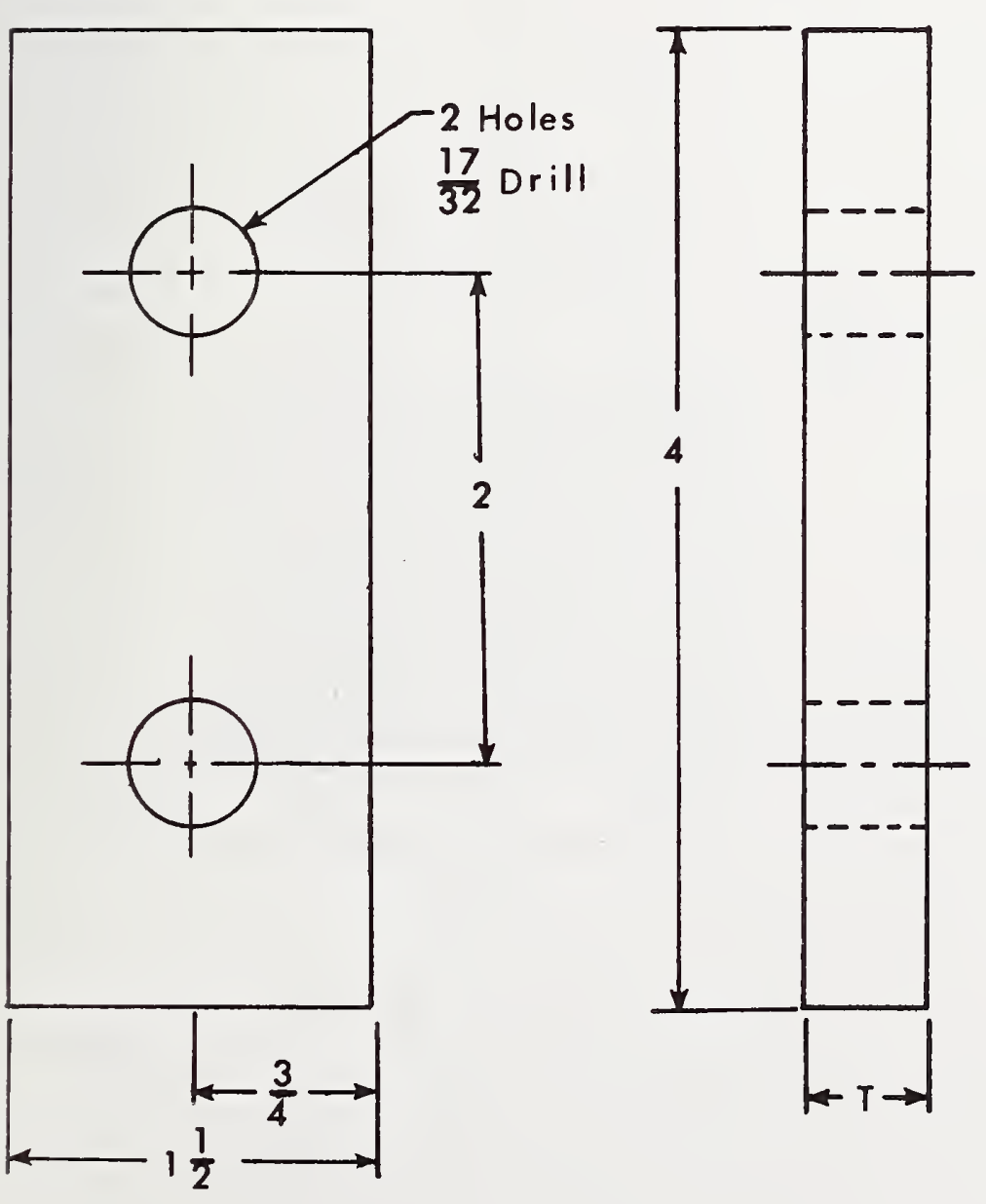

$\begin{array}{lll}\text { For } \frac{3}{8} \text { Fasteners, } T=0.375 & \begin{array}{l}+.005 \\ -.000\end{array} \\ \text { For } \frac{1}{2} \text { Fasteners, } T=0.500 & \begin{array}{l}+.005 \\ -.000\end{array}\end{array}$

Part No. 4

Spacer

Material: 0-2 Tool Steel

1 Required for Each Size Fastener

Fig. A12 


$$
45
$$$$
\text { p. }
$$ 

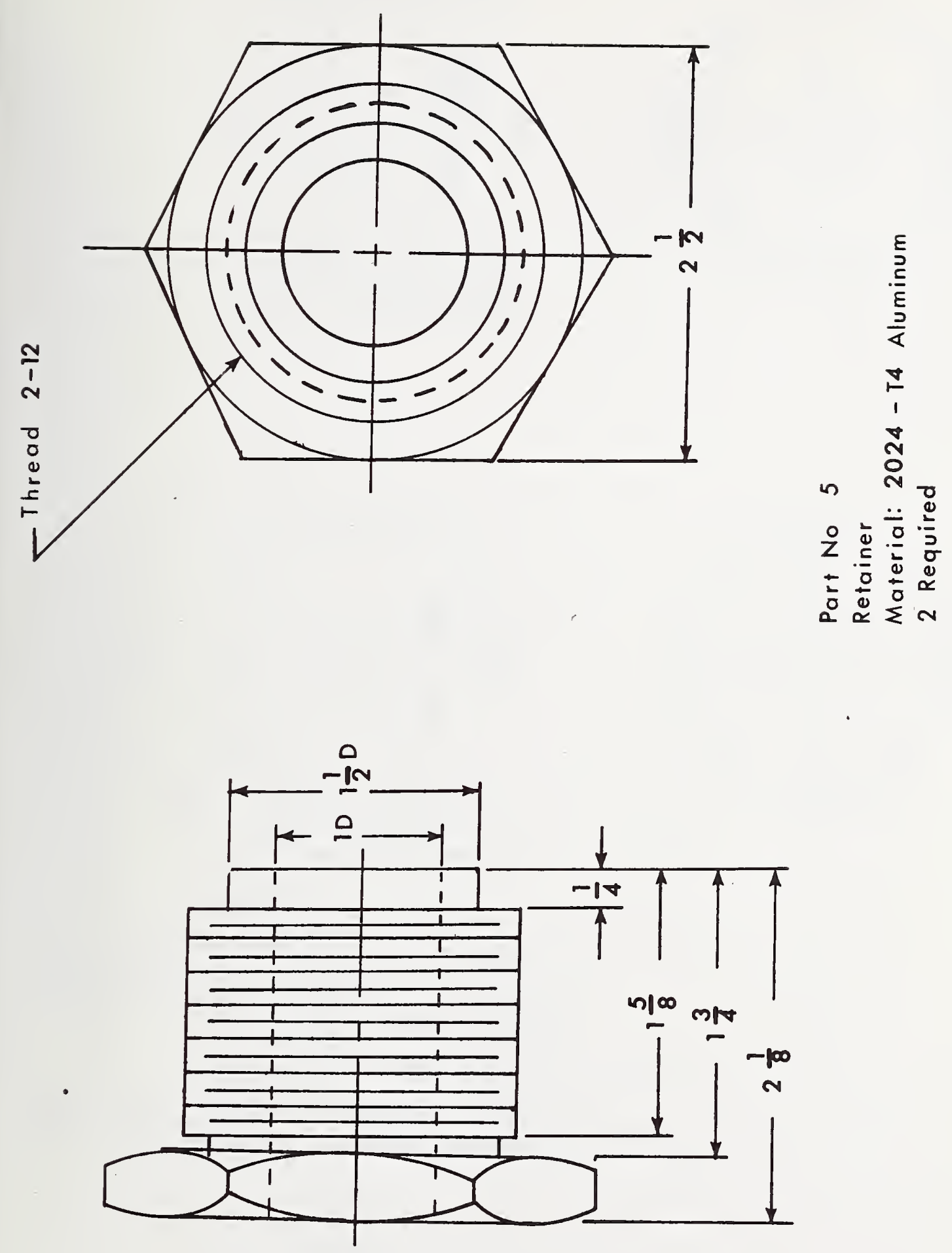

$\frac{1}{4}$
$\dot{\text { ó }}$ 


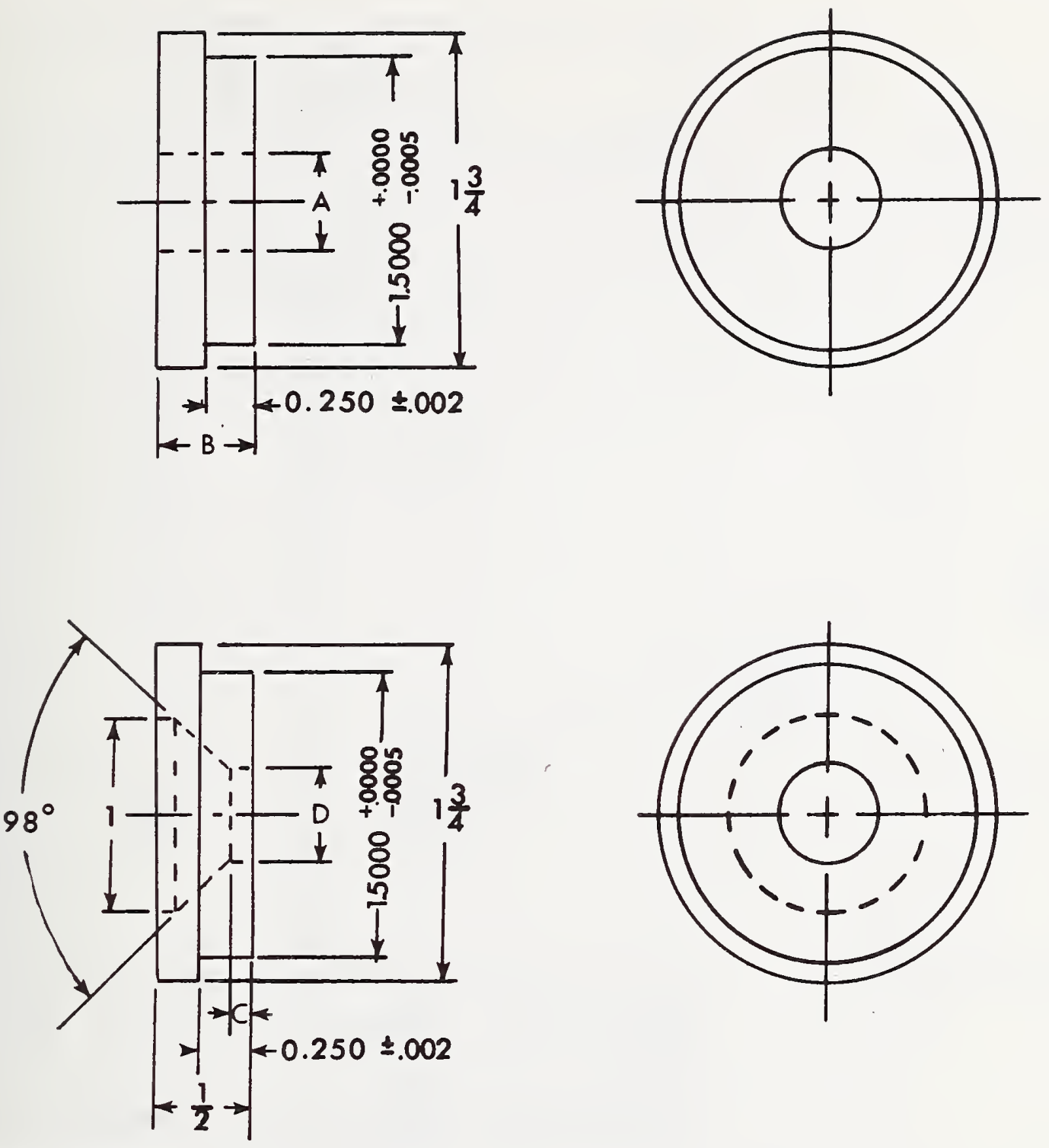

\begin{tabular}{|c|c|c|c|c|}
\hline Fastener & $A$ & B & C & $D$ \\
\hline$\frac{3}{8}$ & 0.375 & $\frac{3}{8}$ & 0.040 & 0.394 \\
\hline$\frac{1}{2}$ & 0.500 & $\overline{2}$ & 0.050 & 0.525 \\
\hline Tolerance & $\begin{array}{l}+.002 \\
-.000\end{array}$ & & \pm .005 & \pm .005 \\
\hline
\end{tabular}

Part No 6

Insert

Material: A|SI 4340 Steel

$R_{c}$ 45-50

1 Each Required for Each

Size Fastener 



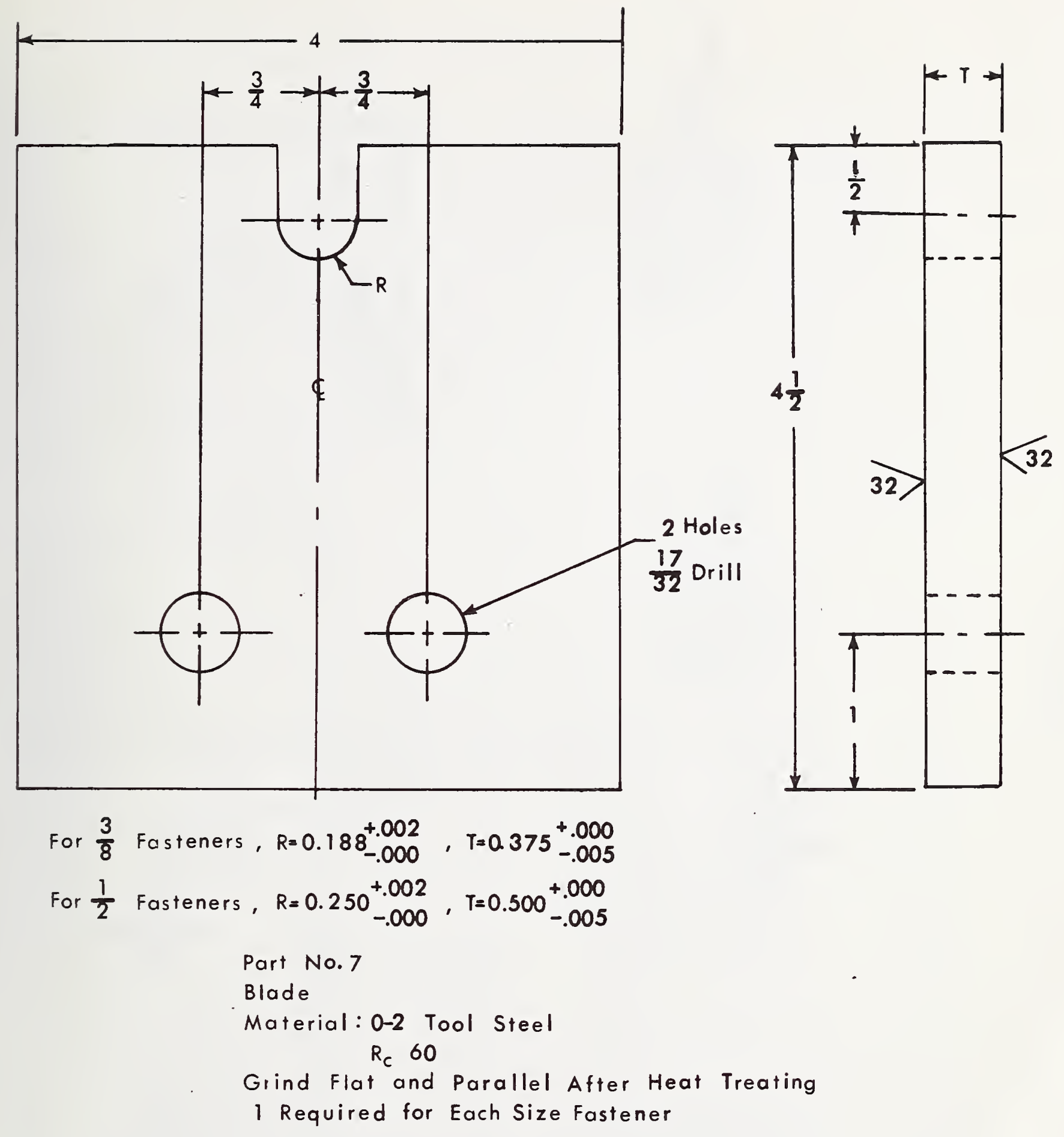

Fig. A 15 



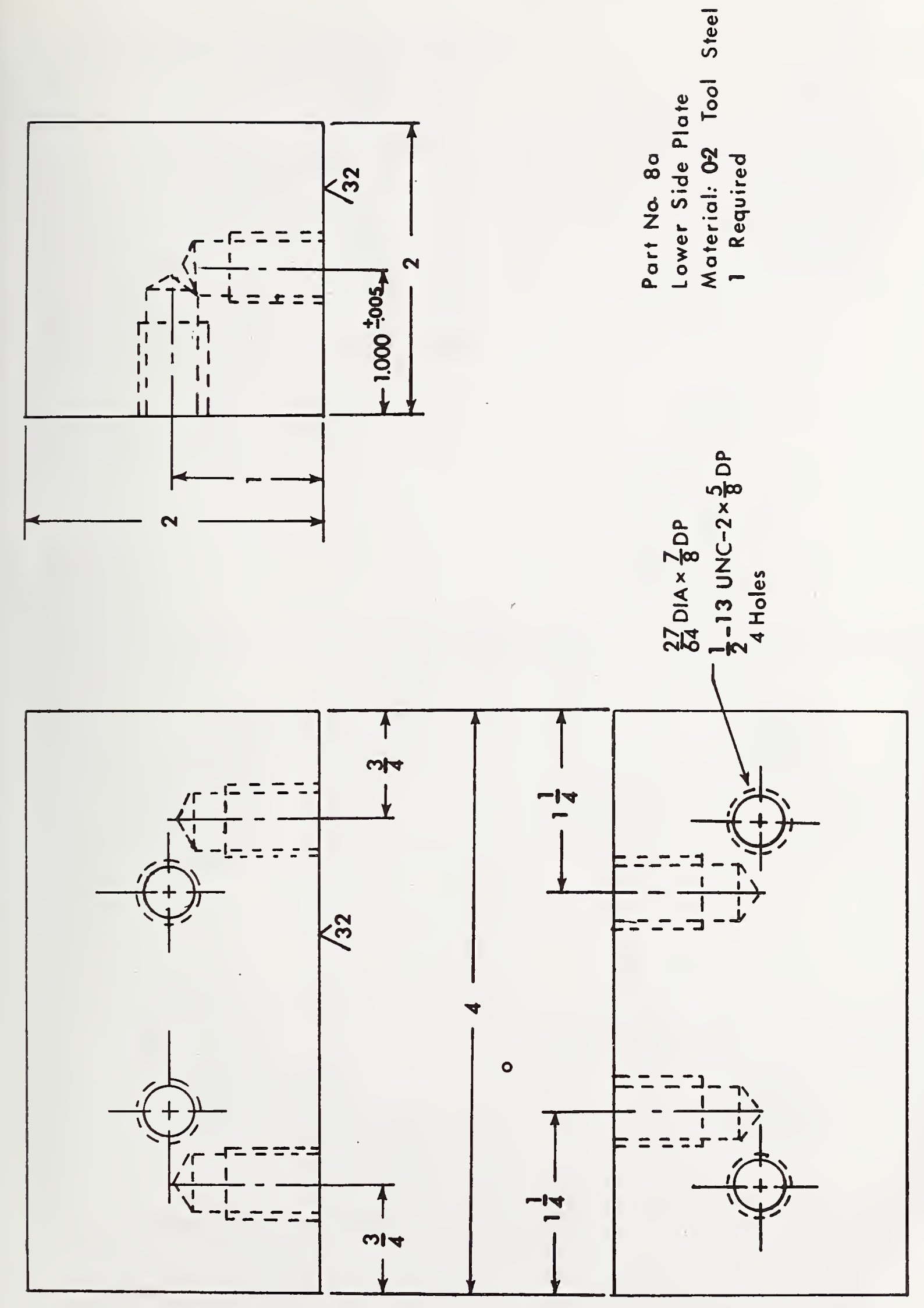

$\frac{0}{4}$
í 


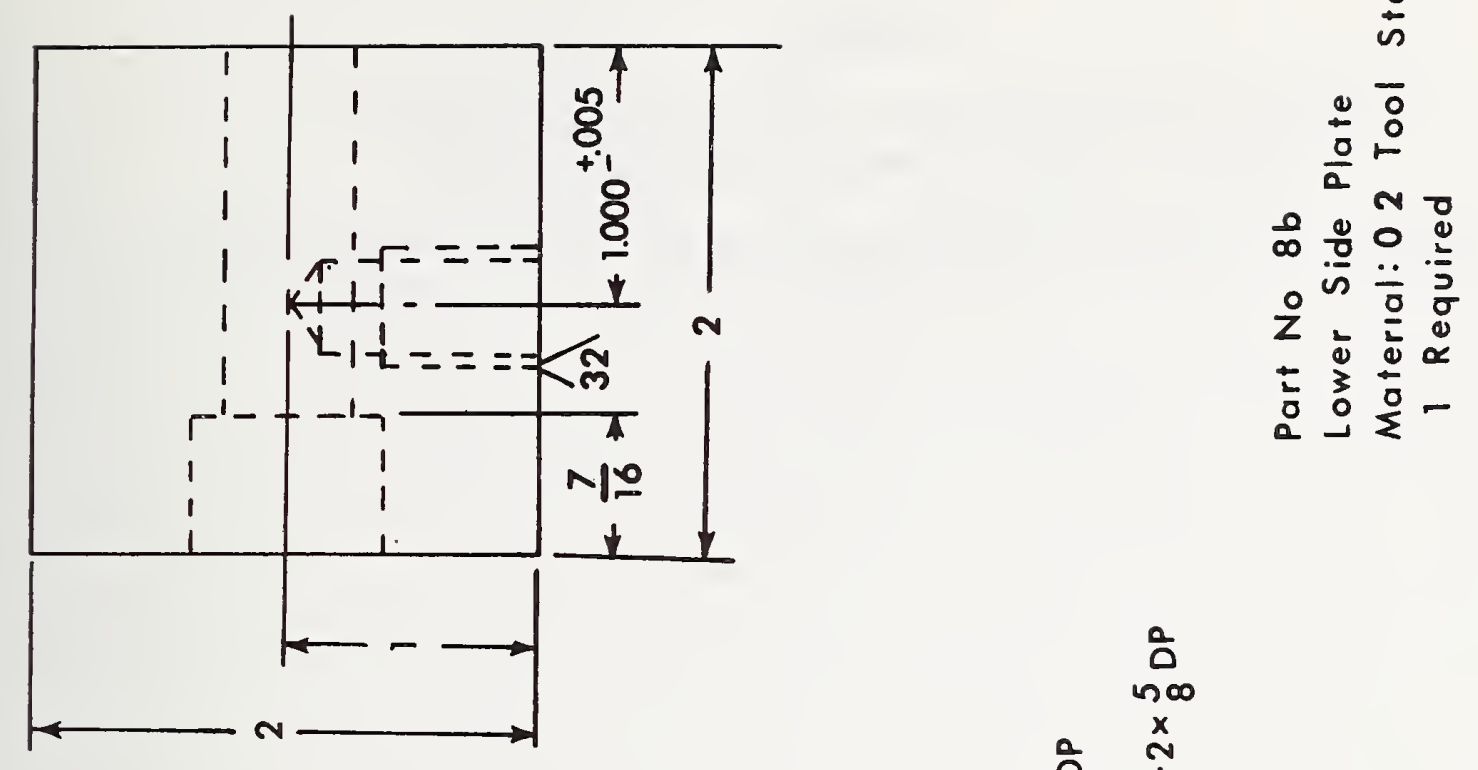

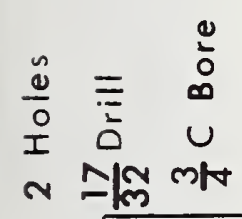

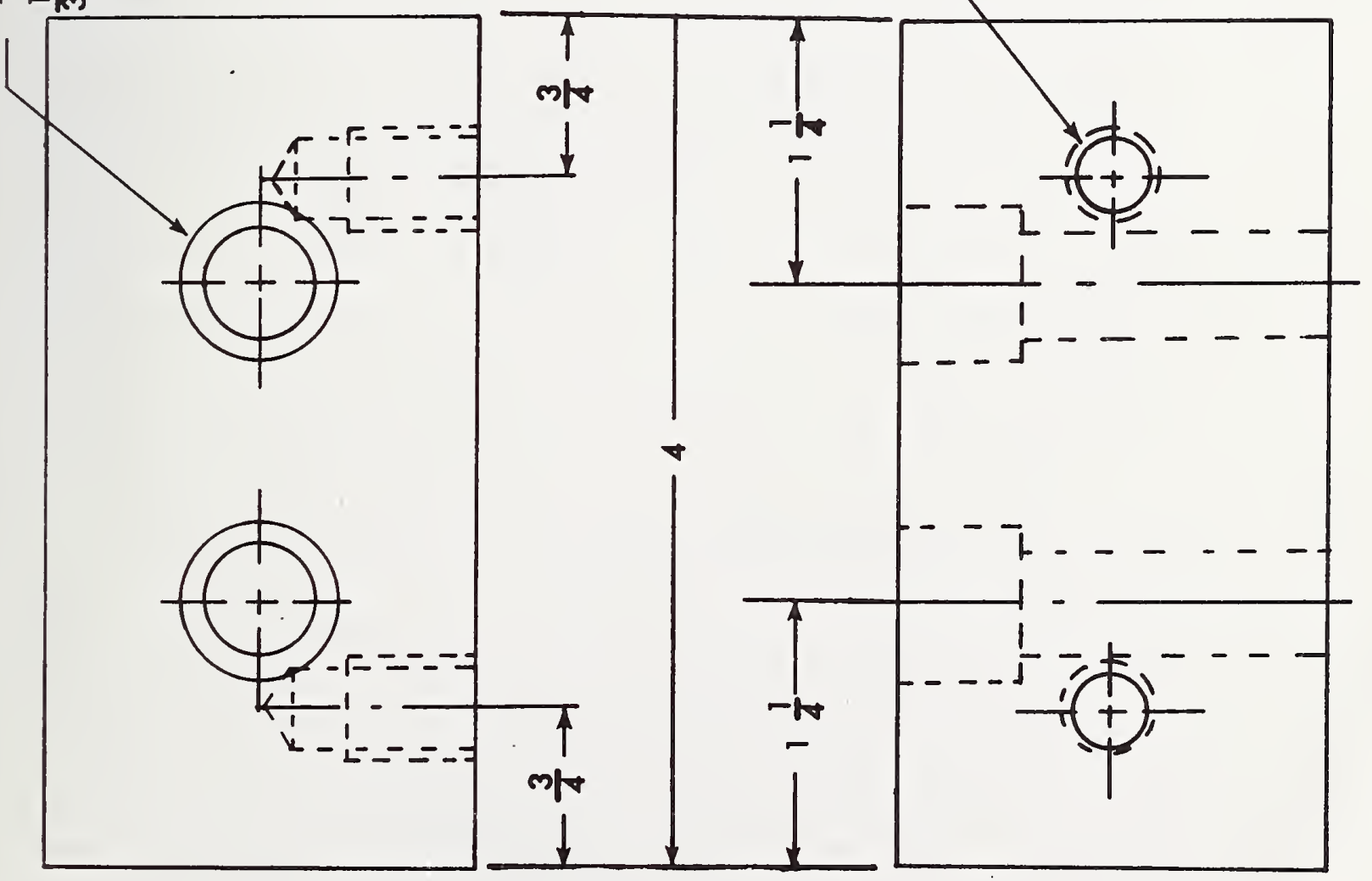





\section{APPENDIX B}

Tension-Bending Fatigue Test Fixtures for 0.250-in

Protruding Head Threaded Airframe Fasteners

Detailed drawings for the fixtures used for the tests described in this paper are given in figures B1 to B6. 
$\because$ 


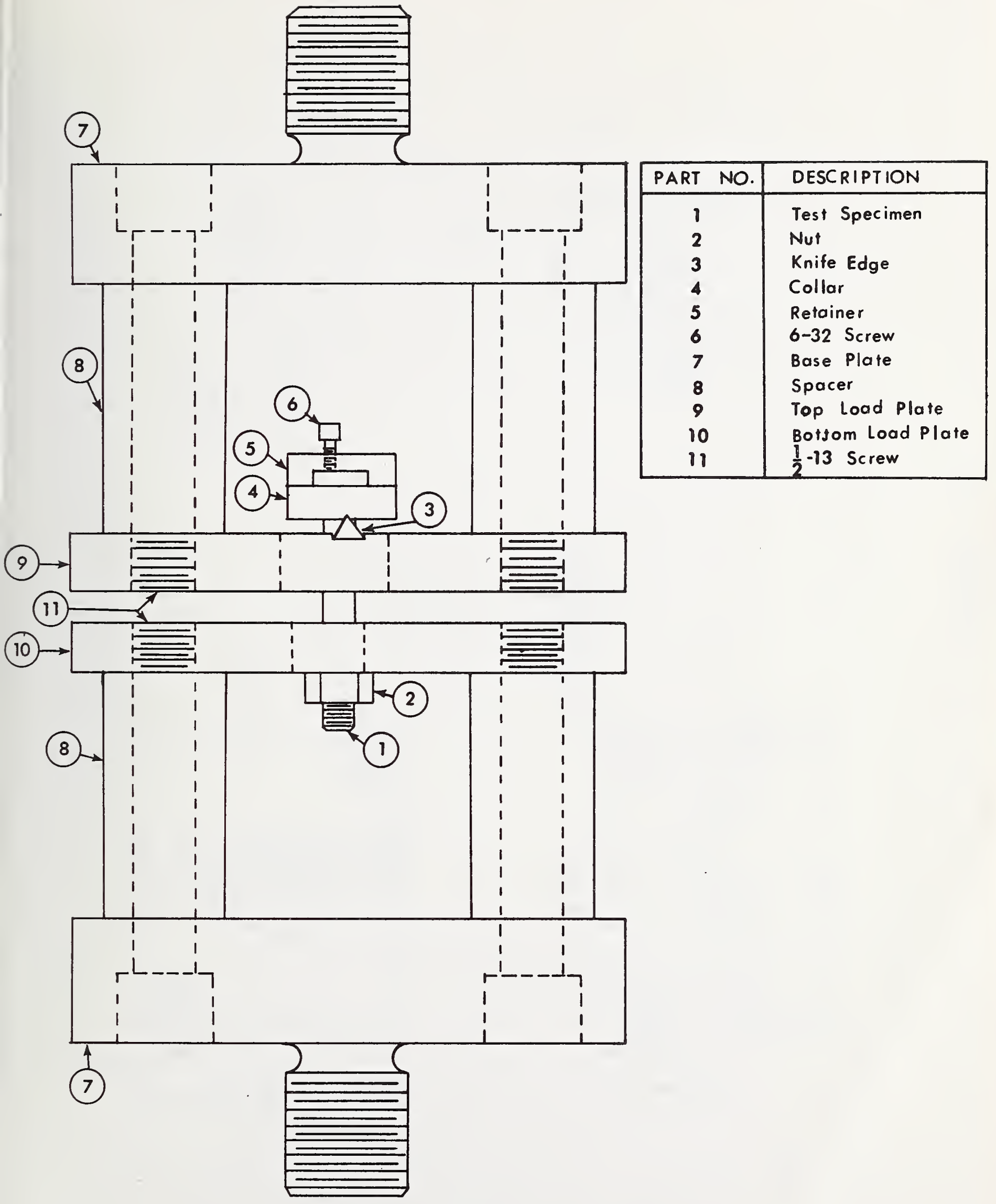

Fig. B 1-Tension-Bending Fixtures, Assembly 


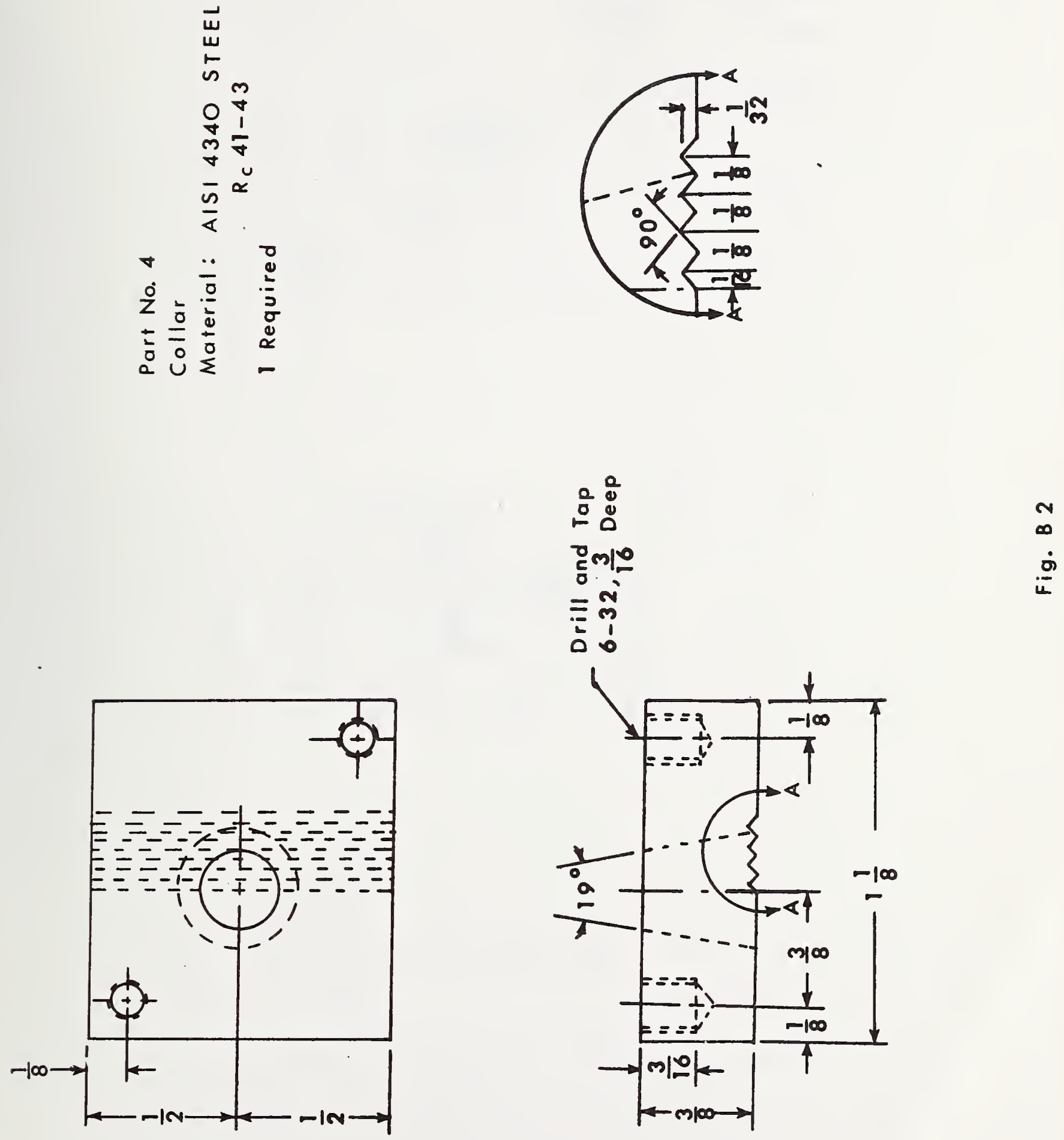

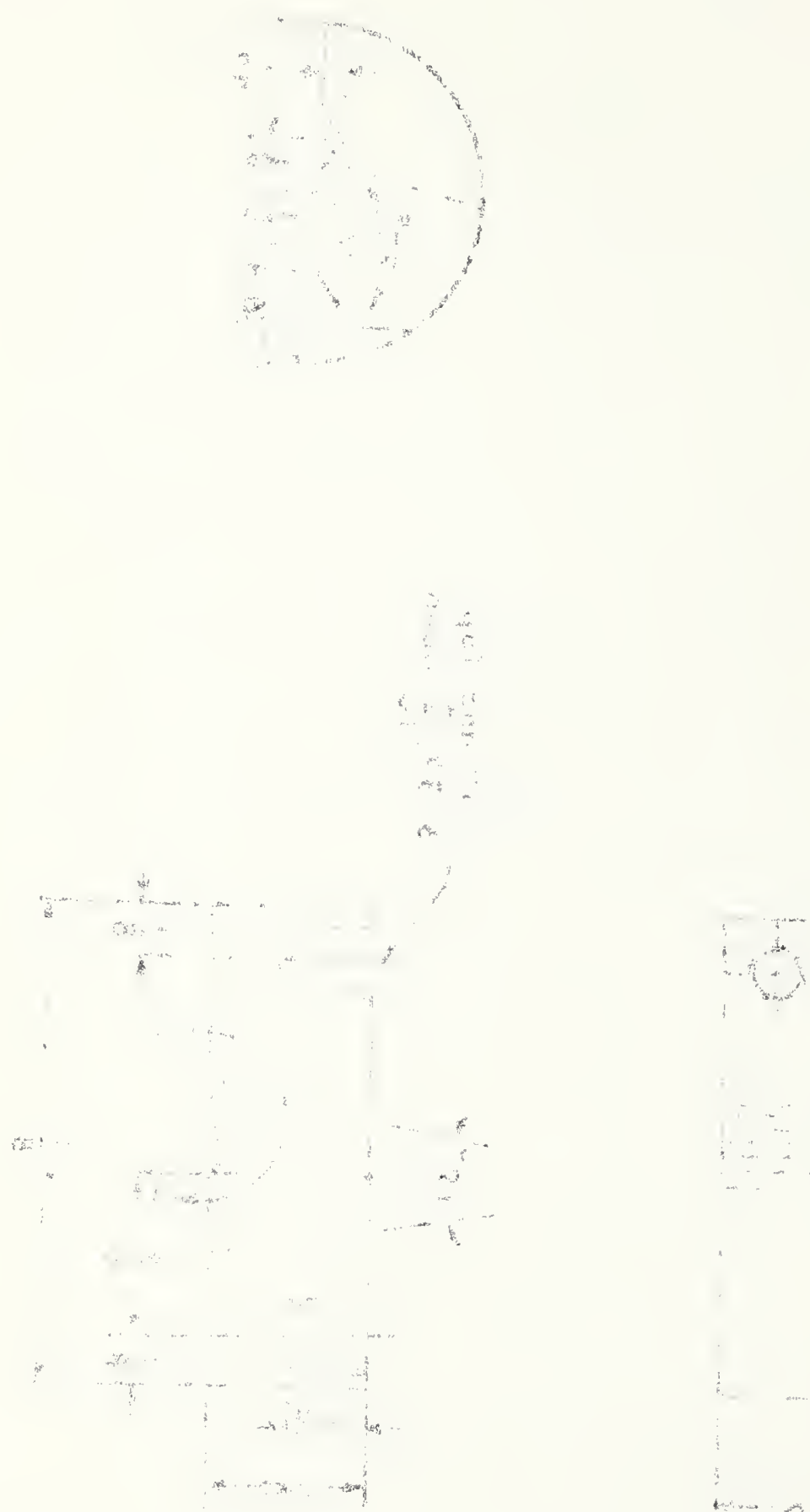

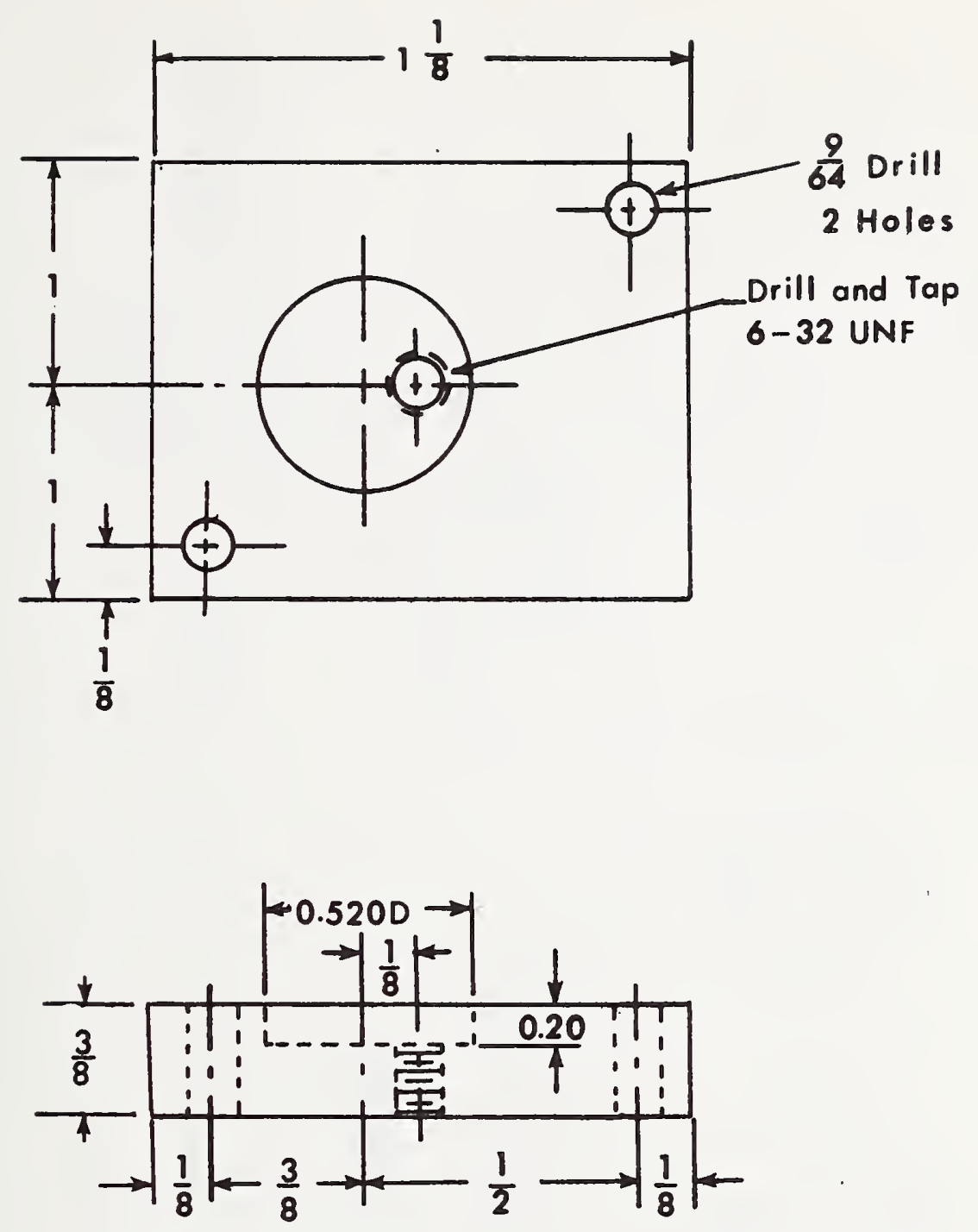

Part No. 5

Retainer

Material: Cold Rolled Steel

1 Required

Fig. B3 



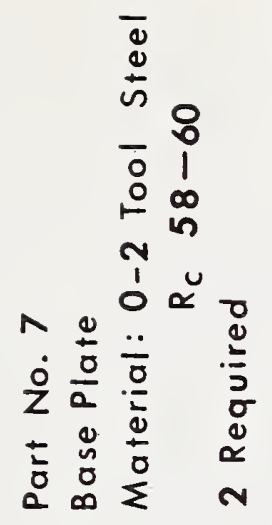

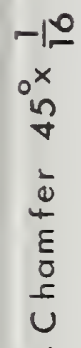

㘣
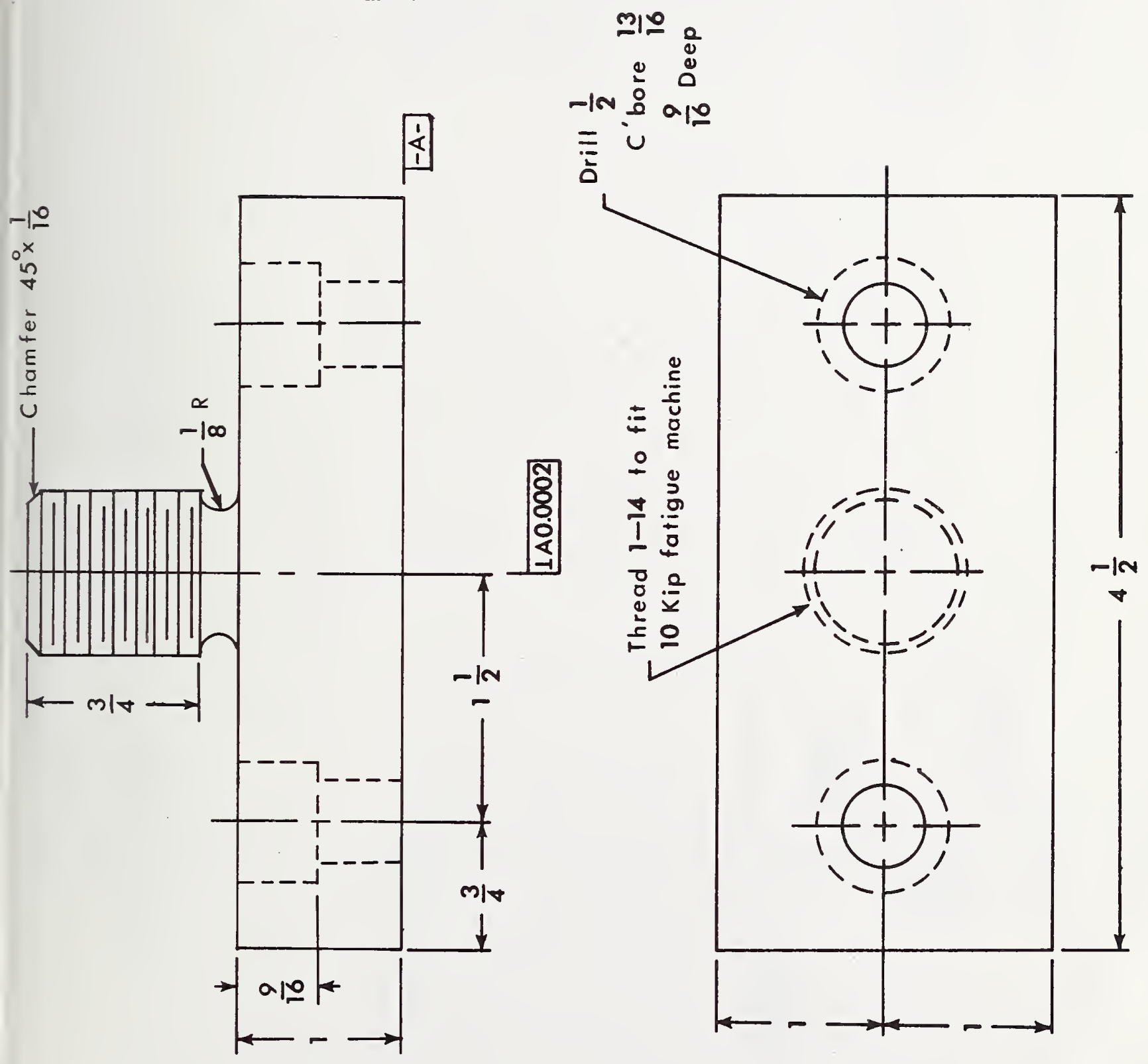

$\dot{0}$
$\dot{\varphi}$ 


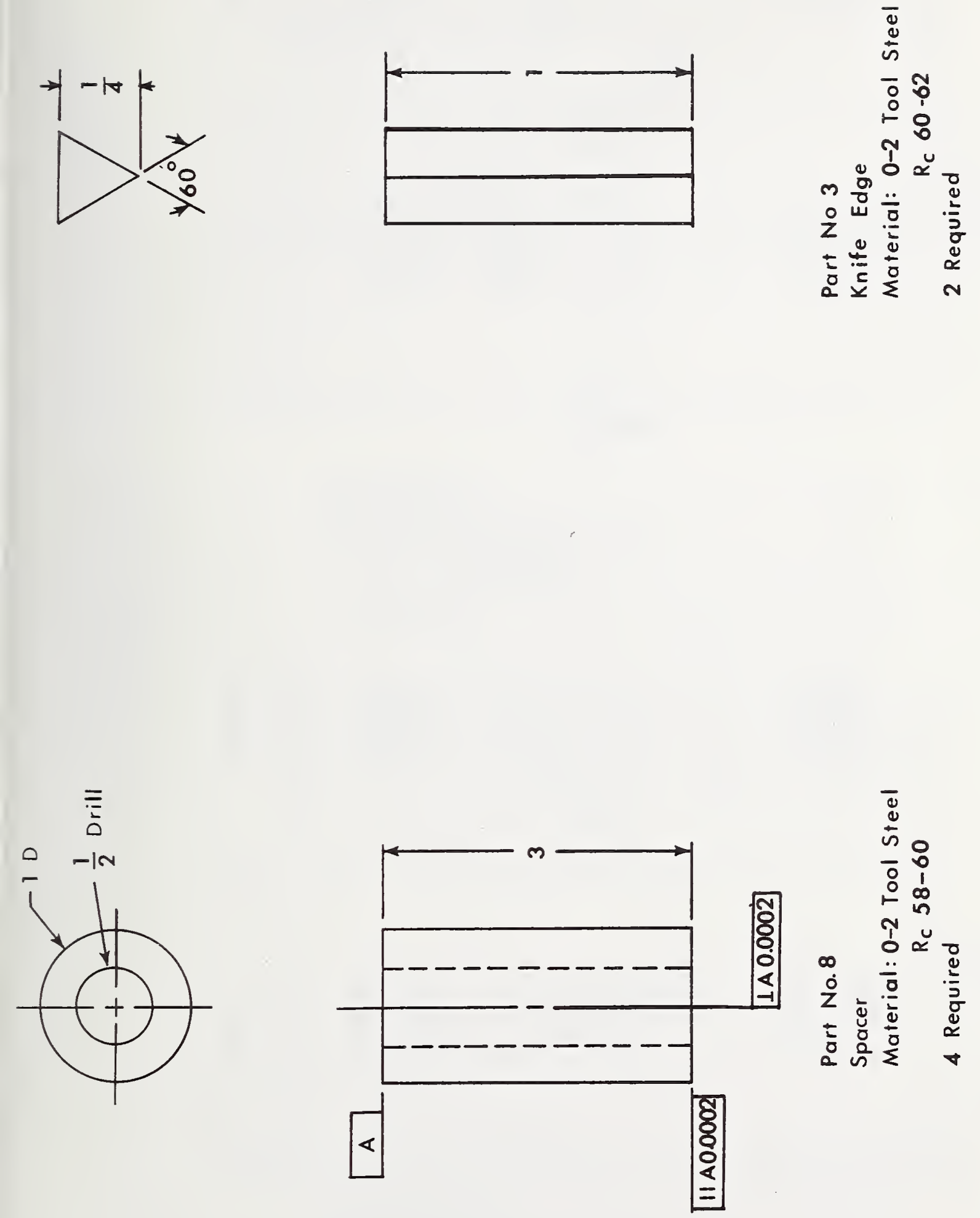


NBS-114A (REV. 7.73)

\begin{tabular}{|c|c|c|}
\hline $\begin{array}{l}\text { U.S. DEPT. OF COMM. } \\
\text { BIBLIOGRAPHIC DATA } \\
\text { SHEET }\end{array}$ & $\begin{array}{l}\text { 1. PUBL.ICATION OR REPORT NO. } \\
\text { NBSIR } 74-465\end{array}$ & 3. Recipient's Accession No. \\
\hline \multirow{2}{*}{\multicolumn{2}{|c|}{$\begin{array}{l}\text { 4. TITLE AND SUBTITLE } \\
\text { Shear and Tension-Bending Fatigue Test Methods for } \\
\text { Threaded Airframe Fasteners }\end{array}$}} & 5. Publication Date \\
\hline & & 6. Performing Organization Code \\
\hline \multirow{3}{*}{\multicolumn{2}{|c|}{$\begin{array}{l}\text { 7. AUTHOR(S) } \\
\text { Danie1 J. Chwirut, Donald E. Marlowe, and James S. Steel } \\
\text { 9. PERFORMING ORGANIZATION NAME AND ADDRESS } \\
\text { NATIONAL BUREAU OF STANDARDS } \\
\text { DEPARTMENT OF COMMERCE } \\
\text { WASHINGTON, D.C. } 20234\end{array}$}} & $\begin{array}{l}\text { 8. Performing Organ. Report No. } \\
\text { NBSIR } 74-465\end{array}$ \\
\hline & & $\begin{array}{l}\text { 10. Project/Task/Work Unit No. } \\
2130448\end{array}$ \\
\hline & & $\begin{array}{l}\text { 11. Contract/Grant No. } \\
\text { NADC Project Order No. } \\
\text { PO-8-0033 }\end{array}$ \\
\hline \multirow{2}{*}{\multicolumn{2}{|c|}{$\begin{array}{l}\text { 12. Sponsoring Organization Name and Complete Address (Street, City, State, ZIP) } \\
\text { Aero Structures Department } \\
\text { Naval Air Development Center } \\
\text { Department of the Navy } \\
\text { Warminster, Pennsylvania } 18974\end{array}$}} & $\begin{array}{l}\text { 13. Type of Report \& Period } \\
\text { Covered } \\
\text { Final }\end{array}$ \\
\hline & & 14. Sponsoring Agency Code \\
\hline
\end{tabular}

15. SUPPLEMENTARY NOTES

16. ABSTRACT (A 200-word or less factual summary of most significant information. If document includes a significant bibliography or literature survey, mention it here.)

Fatigue test methods for threaded airframe fasteners loaded in other than direct tension are described. The types of loading considered are single shear, double shear, and tension-bending. The test fixtures used in these tests are described. Results of tests on lots of fasteners from different manufacturers indicate that fasteners considered identical on the basis of direct tension procurement tests exhibit different fatigue life characteristics when loaded in shear and/or tension-bending. Thus the test methods described herein may be of future value as procurement tests for airframe fasteners.

17. KEY WORDS (six to twelve entries; alphabetical order; capitalize only the first letter of the first key word unless a proper name; separated by semicolons)

Airframe fastener; double shear; fatigue; single shear; tension-bending; test methods

18. AVAILABILITY

$\overline{\mathrm{x}}$ Unlimited

For Official Distribution. Do Not Release to NTIS

Order From Sup. of Doc., U.S. Government Printing Office Washington, D.C. 20402, SD Cat. No. C13

Order From National Technical Information Service (NTIS) Springfield, Virginia 22 I 51

\begin{tabular}{|l|l|}
\hline $\begin{array}{l}\text { 19. SECURITY CLASS } \\
\text { (THIS REPURT) }\end{array}$ & 21. NO. OF PAGES \\
UNCL ASSIFIED & \\
\hline $\begin{array}{l}\text { 20. SECURITY CLASS } \\
\text { (THIS PAGE) }\end{array}$ & 22. Price \\
UNCLASSIFIED & \\
\hline
\end{tabular}




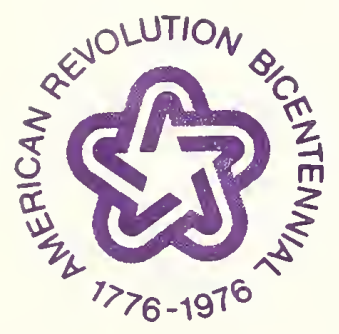





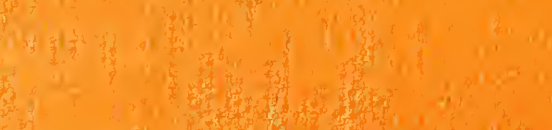

(1)

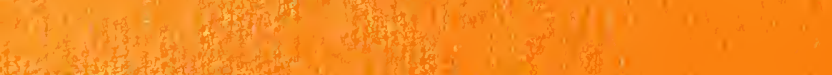

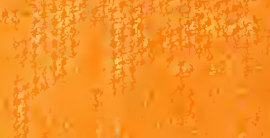

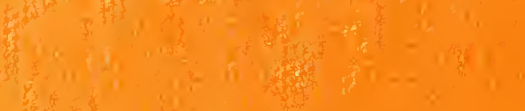

ty

$\left(7, x^{2}, y^{4}, y^{4}=\right.$

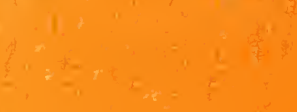

$\frac{1}{2} \cdot=$

$t^{2}$

$x=\ldots$

(1.

$\because$

,

ats

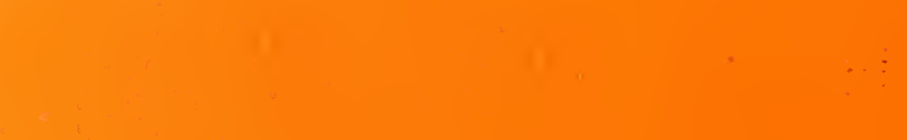

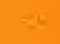

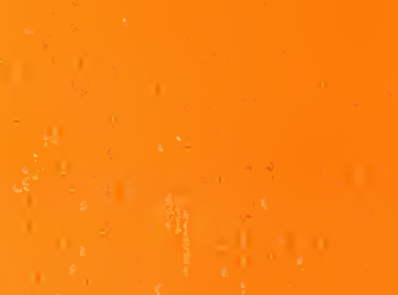

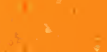

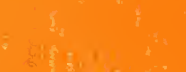

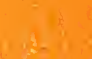

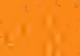

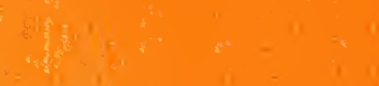

(f)

$+4$

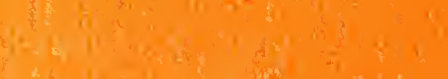

(1)

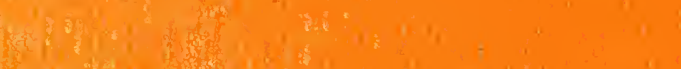

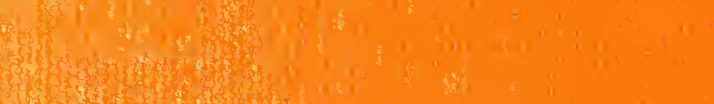

Thing

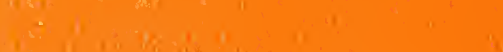

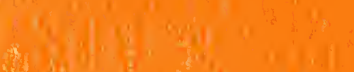

the

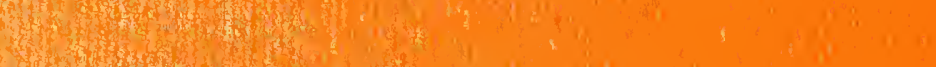

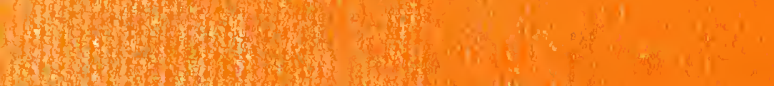

H.

$x^{2}$ 